\title{
Relaxor behaviour and phase transition of perovskite ferroelectrics-type complex oxides (1-x) $\mathrm{Na}_{0.5} \mathrm{Bi}_{0.5} \mathrm{TiO}_{3}-x \mathrm{CaTiO}_{3}$ system
}

\author{
Roy ROUKOS*, Nissrine ZAITER, Denis CHAUMONT
}

\author{
Laboratoire Interdisciplinaire Carnot de Bourgogne UMR 6303 CNRS, \\ Université de Bourgogne, 9 Avenue Alain Savary, 21078 Dijon, France
}

Received: October 23, 2017; Revised: February 20, 2018; Accepted: February 27, 2018

(C) The Author(s) 2018. This article is published with open access at Springerlink.com

\begin{abstract}
Polycrystalline powders of $(1-x) \mathrm{Na}_{0.5} \mathrm{Bi}_{0.5} \mathrm{TiO}_{3}-x \mathrm{CaTiO}_{3}((1-x) \mathrm{NBT}-x \mathrm{CT}, 0 \leqslant x \leqslant 0.55)$ have been synthesized by solid state route. The effects of simultaneous substitution of $\mathrm{Na}^{+} / \mathrm{Bi}^{3+}$ at A-site in NBT on structural and dielectric properties were investigated. X-ray diffraction analysis revealed the phase transition from rhombohedral structure $(x=0)$ to orthorhombic structure $(x \geqslant$ 0.15 ). A distinct behaviour in dielectric properties was obtained, where for $x=0$, a normal ferroelectric behaviour was observed, whereas for $x \geqslant 0.15$, a broad dielectric anomaly was revealed such that the maximum temperature $\left(T_{\mathrm{m}}\right)$ strongly depended on the frequency and shifted towards low temperature with CT. The dielectric dispersion indicated a relaxor behaviour revealed by the degree of diffuseness and modelled via Vogel-Fulcher relation. The study highlighted the relaxor behaviour as a function of frequency and proved the transformation from a relaxor high-frequency dependence to a paraelectric phase at temperature $T_{\mathrm{s}}$. The distinct variation of the Raman spectra at room temperature was correlated with X-ray diffraction results and proved the already mentioned transition. On heating $\left(-193-500{ }^{\circ} \mathrm{C}\right)$, the Raman spectra confirmed the structural stability (Pnma) of the materials. The phonon behaviour for $x=0.15$ was discussed in terms of the appearance of polar nanoregions (PNRs) into a non-polar orthorhombic matrix responsible of the relaxor behaviour. For $x=0.20$, unchanged phonon behaviour confirmed the variation in dielectric behaviour where the solids transformed from a relaxor to a paraelectric state without structural phase transition.
\end{abstract}

Keywords: relaxor behaviour; dielectric properties; Vogel-Fulcher relationship; polar nanoregions (PNRs); X-ray diffraction; Raman spectroscopy

\section{Introduction}

Relaxor ferroelectric material studies are in continuous increase and development from recent years till now. They are mainly used in devices for microelectronic applications, especially in capacitors and actuators [1].

* Corresponding author.

E-mail: roy.roukos@gmail.com
Most of these devices are manufactured with lead-based compounds such as $\mathrm{Pb}\left(\mathrm{Mg}_{1 / 3} \mathrm{Nb}_{2 / 3}\right) \mathrm{O}_{3}$ (PMN) [2]. This material is a prototypical relaxor with $\mathrm{ABO}_{3}$ perovskite structure where the B-site is occupied by two kinds of heterovalent cations. The scientific community has been investigating many $\mathrm{Pb}$-free systems exhibiting relaxor behaviour as an alternative substitute for the lead-based relaxor. $\mathrm{Na}_{0.5} \mathrm{Bi}_{0.5} \mathrm{TiO}_{3}$ (NBT) is one of the lead-free relaxor ferroelectric materials which is used 
for high temperature applications and can serve as a good substitute of lead-based ceramics. Several approaches to improve the piezoelectric and dielectric properties of this material for new morphotropic phase boundary (MPB) in the NBT-based solid solutions were conducted. Among these various systems, $(1-x) \mathrm{Na}_{0.5} \mathrm{Bi}_{0.5} \mathrm{TiO}_{3}-x \mathrm{BaTiO}_{3}(\mathrm{NBT}-\mathrm{BT})$ have attracted considerable attention due to the existence of rhombohedral-tetragonal MPB near $x=0.06$ [3-5]. In comparison with other systems such as pure NBT, NBT-BT show excellent piezoelectric and ferroelectric properties near MPB [6,7]. This region can be created, destroyed, or even replaced by another MPB via ferroelectric-to-ferroelectric transition under electrical poling [8] that helps in the understanding of the microstructural mechanism of the enhancement of piezoelectric behaviours.

The exact location of MPB region in some solid solutions remains unclear and not well defined such as in $(1-x) \mathrm{Na}_{0.5} \mathrm{Bi}_{0.5} \mathrm{TiO}_{3}-x \mathrm{SrTiO}_{3} \quad(\mathrm{NBT}-\mathrm{ST})$ system. Gomah-Pettry et al. [9] reported that MPB is situated at $x=0.25$, whereas Hiruma et al. [10] attributed that it is at around $x=0.26-0.28$, and recently, Rout et al. [11] found that it is at $x=0.20$. In contrast, Krauss et al. [12] reported that there is no structural evidence of MPB. Note that the NBT-ST system displays the strongest relaxor material at higher concentration of ST, and this is accompanied by an improvement of the dielectric constant at room temperature [11-14].

Most of lead-free relaxor ceramics show relatively high dielectric properties, but unfortunately exhibit a low temperature (transition temperature $<100{ }^{\circ} \mathrm{C}$ ) of the maximum dielectric permittivity $\left(T_{\mathrm{m}}\right)$, limiting their utilization. Recently, Jin et al. [15] reported that the $\mathrm{Fe}^{3+}$-doped $0.5 \mathrm{Ba}\left(\mathrm{Zr}_{0.2} \mathrm{Ti}_{0.8}\right) \mathrm{O}_{3}-0.5\left(\mathrm{Ba}_{0.7} \mathrm{Ca}_{0.3}\right) \mathrm{TiO}_{3}$ (BZT-0.5BCT) system shows remarkably high electrostrictive coefficient ( $Q_{33}$ between 0.04 and $0.05 \mathrm{~m}^{4} / \mathrm{C}^{2}$ ) and the temperature corresponding to maximum permittivity $\left(T_{\mathrm{m}}\right)$ shifts towards low temperature by $37{ }^{\circ} \mathrm{C}$ per $1 \%$ of $\mathrm{Fe}^{3+}$ ions, showing weak relaxor characteristic. Alternatively, a comparable system to $(1-x) \mathrm{NBT}-x \mathrm{BT}$ is $(1-x) \mathrm{BiScO}_{3}-x \mathrm{PbTiO}_{3}$ [16]. Such a system reveales an MPB around $x=0.64$ where the rhombohedral and tetragonal phases coexist such that high Curie temperature $\left(T_{\mathrm{C}}\right)$ and high dielectric constant are obtained. This temperature $\left(T_{\mathrm{C}}\right)$ is shifted towards much higher temperature and the maximum dielectric constant increases as $x$ content increases.

Such an enhancement of piezoelectric properties is related to the change in crystallographic symmetry and also to the lattice deformation as well as the differing in the tilt magnitude of perovskite octahedra, recently proved in the $(1-x) \mathrm{BiFeO}_{3}-x \mathrm{BaTiO}_{3}$ ceramics [17]. Lately, new multi-component systems of piezoelectric materials have been developed, the $0.93 \mathrm{NBT}-$ $0.065 \mathrm{BT}-x \mathrm{Bi}_{2} \mathrm{FeCrO}_{6}$ [18], where an appropriate doping induces the enhancement of piezoelectric and ferroelectric properties of the materials.

One of the important features of relaxor is the ability to transform to a ferroelectric state under the presence of an electric field at low temperature. Recently, Jo et al. [19] reported that the phase stability of the poled $0.94 \mathrm{NBT}-0.06 \mathrm{BT}$ ceramic is related to the detextured macroscopic ferroelectric domains which are dissociated into nanoscale entities. This fragmentation is an indicator of ferroelectric-relaxor transition where the depolarization temperature $\left(T_{\mathrm{d}}\right)$ coincides with the freezing temperature $\left(T_{\mathrm{f}}\right)$ characteristic of relaxor behaviour.

From a physical point of view, a relaxor is defined as a material possessing a colossal, broad dielectric constant, and strongly frequency dependent such that the temperature $T_{\mathrm{m}}$ of maximum permittivity shifts to higher values as the frequency increases [20]. Despite that this behaviour is observed only in materials where the same crystallographic site is occupied by at least two cations, the substitution may be homovalent as $\mathrm{Ba}\left(\mathrm{Ti}_{1-x} \mathrm{Zr}_{x}\right) \mathrm{O}_{3}$ [21,22] and $\mathrm{Ba}\left(\mathrm{Ti}_{1-x} \mathrm{Sn}_{x}\right) \mathrm{O}_{3}$ [23], or heterovalent as $\mathrm{PMN}$ and $\mathrm{Pb}\left(\mathrm{Sc}_{1 / 2} \mathrm{Ta}_{1 / 2}\right) \mathrm{O}_{3}$ (PST) [24]. Much complex cases also exist where such substitution leads to some vacancy defects responsible of relaxor behaviour like PLZT $\left(\mathrm{Pb}_{1-x} \mathrm{La}_{x}\left(\mathrm{Zr}_{y} \mathrm{Ti}_{1-y}\right) \mathrm{O}_{3}\right)$ [25,26].

In lead-based relaxor materials, the influence of the degree of chemical order has been demonstrated by several studies [27]. This order may vary by heat treatment from either side of a temperature called chemical order temperature. $\mathrm{Pb}\left(\mathrm{Sc}_{1 / 2} \mathrm{Ta}_{1 / 2}\right) \mathrm{O}_{3}$ [27], is a good example of this kind of order. It can be produced with a controllable chemical order as annealing and quenching. In this case, the degree of order is experimentally adjusted by heat, unlike the independent case of PMN. This chemical order has evidently a strong influence on the dielectric specifically ferroelectric properties.

Despite the intensive research on the physical properties of relaxor, the microscopic nature of $\mathrm{PMN}$ is not completely revealed. However, one of the most important microscopic properties of relaxor is directly related to polar nanoregions (PNRs). This was initially 
proved by Burns and Dacol [28] through the deviation of refractive index $n(T)$ which is proportional to the polarization $\left(P_{\mathrm{s}}\right)$ of the material. In this case, the materials acquire a local polarization occurring in PNRs. The existence of PNRs was confirmed later by high-resolution X-ray diffraction, neutron diffraction, synchrotron on PMN [29-32], and specific heat measurements $\left(C_{\mathrm{p}}\right)$ between 2 and $500 \mathrm{~K}$ [33]. The participation of PNRs to the huge dielectric response is still unrevealed.

Regarding structure, a large number of relaxor materials show centrosymmetric crystal structure, even the cubic one, with no macroscopic polarization. X-ray diffraction studies show that the crystal structure appears to be independent of temperature even for $T_{\mathrm{m}}$. Other studies show the existence of PNRs with reduced phases where the polarization is not zero. Bonneau et al. [30] have demonstrated the presence of polar short-range order in the PMN using high-resolution $\mathrm{X}$-ray diffraction. At very low temperature around $5 \mathrm{~K}$, de Mathan et al. [34] interpreted X-ray diffraction pattern as small regions of rhombohedral symmetry $(R 3 m)$ into a paraelectric matrix of cubic symmetry $(P m \overline{3} m)$. The size of these regions is limited to the nano-order and the polarization is randomly oriented among different regions. Such a heterostructure at low temperature is necessary in the relaxor properties. These PNRs extend over a wide temperature range. The boundary between the polar state and the paraelectric state is called Burns temperature $T_{\mathrm{B}}$. In the vicinity of $T_{\mathrm{B}}$, these nanoregions are strongly temperature dependent and their number increases as the temperature decreases especially at $T<T_{\mathrm{B}}$. Correlatively, their size increases as the temperature decreases even below the critical temperature [35]. These variations are detected by elastic neutron scattering [36] and by observation of the area of materials via piezoresponce force microscopy (PFM) [37]. Subsequent studies [38-41] used higher performance techniques such as X-ray diffuse scattering and neutron scattering to describe the growth mechanism of nanoregions as the temperature decreases.

Currently, the majority of new relaxors are developed by combining three or more cations in the A-site of NBT. The A-site of NBT is equally occupied by $\mathrm{Na}^{+}$ and $\mathrm{Bi}^{3+}$ ions which is unusual in most of perovskite structure. Several studies were dedicated to investigate the role of the A-site in the relaxor phenomenon and increased the interest in this site. Several explanations were reported describing the origin of this behaviour
[42]. In the mission of understanding the relaxor behaviour, various NBT solid solutions modified on A-site with various cations or perovskite such as NBT-ST [11,13,43], NBT- $\mathrm{K}_{0.5} \mathrm{Bi}_{0.5} \mathrm{TiO}_{3}$ (KBT) [44], and NBT-Ba( $\left(\mathrm{Al}_{1 / 2} \mathrm{Sb}_{1 / 2}\right) \mathrm{O}_{3}$ [45] were studied and showed that the relaxor behaviour is generated by increasing the substitution. Some of these systems show anomalies corresponding to phase transition to an unusual piezoelectric and ferroelectric near MPB. Based on extensive literature about relaxor behaviour and the comparison between the effect of the three dopants $\left(\mathrm{Ba}^{2+}, \mathrm{Sr}^{2+}\right.$, and $\left.\mathrm{Ca}^{2+}\right)$ on the different properties of NBT [46], we decided to focus our study on the NBT-CT system. This system was selected for different reasons: as stated earlier, materials derived from NBT are multifunctional materials whose electrical properties are adjusted via the addition of dopants. In fact, several dopants were used to form NBT solid solutions showing MPB. In this study, A-site double substitution of $\mathrm{Na}^{+} / \mathrm{Bi}^{3+}$ by $\mathrm{Ca}^{2+}$ was carried out in order to prevent the diffusion of this cation into B-site and replace the $\mathrm{Ti}^{4+}$ cation, because $\mathrm{Ca}^{2+}$ is easily substituted where it has an ionic radius close to that of the $\mathrm{Na}^{+} / \mathrm{Bi}^{3+}$ which allows this substitution at A-site. Thus the motivation behind studying NBT-CT system is to control the effect of $\mathrm{Ca}^{2+}$ substitution on the enhancement of the relaxor behaviour at A-site. Consequently, this facilitates the study of the relaxor behaviour at these sites. In addition, the use of $\mathrm{Ca}^{2+}$ has so far been shortly investigated [47] and recently some publications concerning this system were published where the research has only focused on studying phase transitions under different experimental conditions. We noticed that there is no evident study of the relaxor made to characterize the physical properties of $(1-x)$ NBT $-x$ CT ceramic system. Furthermore, calcium belongs to the alkaline earth metal family and is in the same column as that of barium $\left(\mathrm{Ba}^{2+}\right)$ and strontium $\left(\mathrm{Sr}^{2+}\right)$, which are widely used for several years as dopants in NBT and lead to useful applications. It is known that $\mathrm{CaTiO}_{3}$ (CT) is a paraelectric material showing an orthorhombic phase at room temperature and able to form a solid solution in A-site of NBT. Hypothetically, it is possible to observe a phase transition from rhombohedral to orthorhombic phase in this system, generating a relaxor behaviour at room temperature. So, it is interesting to exploit this dopant and show the diverse results obtained for the elements of the same column of periodic table.

Despite the recent studies published on the 
$(1-x)$ NBT $-x$ CT system, a detailed study of the relaxor behaviour was not reported. The majority of works mainly focused on the structural phase transition under different experimental conditions. Ranjan et al. [48] showed by neutron diffraction and calculation of phase tilt angle that the $(1-x)$ NBT $-x$ CT system exhibits an orthorhombic phase (Pbnm) for $x \geqslant 0.15$ and rhombohedral phase $(R 3 c)$ for $x \leqslant 0.05$ with a mixture of two phases $(R 3 c+P b n m)$ for $x=0.10$. Moreover, Du et al. [49] demonstrated that this system is susceptible to orthorhombic distortion for $x \geqslant 0.14$ and the MPB was found to lie around $0.08 \leqslant x<$ 0.14. On the contrary, Birks et al. [50] reported the structural properties of poled and unpoled conditions of $(1-x) \mathrm{NBT}-x \mathrm{CT}$ assuming the coexistence of rhombohedral and orthorhombic phases. Despite the various studies of NBT-CT system, the structure of these materials and its link to the obtained physical properties are still not understood and under investigation due to mutual contradicting results. In view of the magical properties showed by this system, this study aims to develop a new lead-free relaxor material with high concentration of CT in A-site beyond the MPB region, in particular investigating the physical nature of $(1-x)$ NBT $-x$ CT system. The influence of CT high concentration on the structural, vibrational, and dielectric properties of the $(1-x) \mathrm{NBT}-x \mathrm{CT}$ system where $x=0$ and $0.15 \leqslant x \leqslant 0.55$ is presented. The system was prepared by a conventional solid state route. The structural phase transition with increasing CT was studied by XRD and Raman spectroscopy. Relaxor behaviour was highlighted for high concentration of CT and its mechanisms were discussed in detail. In addition, high temperature Raman study was carried out for the first time and the obtained results were discussed in agreement with dielectric properties in order to understand the relaxor behaviour.

\section{Experimental details}

The $(1-x)$ NBT $-x$ CT $(x=0,0.15,0.20,0.25,0.27,0.35$, $0.45,0.55)$ powders and ceramic samples were prepared by a conventional solid state reaction method. Stoichiometric amounts of reagent grade powders of $\mathrm{Na}_{2} \mathrm{CO}_{3}$ (Prolabo), $\mathrm{CaCO}_{3}$ (Alfa Aesar), $\mathrm{Bi}_{2} \mathrm{O}_{3}$ (Alfa Aesar), and $\mathrm{TiO}_{2}$ (Alfa Aesar) (purity greater than 99.6\%) were mixed and milled in water with zirconia balls for $2 \mathrm{~h}$ and then dried at $90{ }^{\circ} \mathrm{C}$. The mixtures of materials were homogenized in a dry mortar and firstly calcined at $750{ }^{\circ} \mathrm{C}$ for $4 \mathrm{~h}$, and then another second calcination at $950{ }^{\circ} \mathrm{C}$ for $4 \mathrm{~h}$ was required to complete the reaction. After this procedure, the powders were pressed into pellets with a $13 \mathrm{~mm}$ diameter. The obtained disks were sintered at various temperatures for $1 \mathrm{~h}$ in a confined environment. The sintering temperature increased while increasing the $\mathrm{Ca}$ substitution. The parametric study conducted to determine the "optimal" sintering conditions for each composition showed a change in the sintering temperature as a function of the amount of calcium substituted varying from 1075 to $1200{ }^{\circ} \mathrm{C}$. Note that all the samples are pure with no secondary phase observed in contrast to many other studies.

The ceramic densities of the sintered specimens were measured by the Archimedes method using distilled water. The densities obtained for these ceramics are high between $96 \%$ and $98 \%$.

The structural phase analysis for powders and ceramics was performed by X-ray diffraction (XRD) using a D8 Advance X-ray diffractometer (Vantec detector) with $\mathrm{Cu} \mathrm{K} \alpha$ radiation $(\lambda=1.5405 \AA)$ in the $2 \theta$ range of $20^{\circ}-90^{\circ}$ (a step of $0.017^{\circ}$ and a counting time of $10 \mathrm{~s}$ ). For dielectric properties, ceramics were slightly polished, annealed, and cleaned with acetone. Then each bulk was coated on opposite faces with gold electrode and the measurement was performed using an HP-4284A LCR meter in the temperature range of $70-450 \mathrm{~K}$ at various frequencies $100 \mathrm{~Hz}-1 \mathrm{MHz}$. The Raman spectra study was obtained in a temperature range of $-193-500{ }^{\circ} \mathrm{C}$ using Jobin-Yvon T64000 spectrometer HR (high resolution) equipped with $\mathrm{Ar}$-ion laser operated at $514.5 \mathrm{~nm}$ and adjusted at $20 \mathrm{~mW}$ for excitation with liquid $\mathrm{N}_{2}$-cooled system couple device detector. Raman analysis was carried out in the frequency range 4.00 to $700 \mathrm{~cm}^{-1}$. The Fityk is a curve and peak fitting software that was used in order to fit the spectra with a Lorentzian and Gaussian line shape.

\section{Results and discussion}

\section{1 Phase structure changes of (1-x)NBT-xCT ( $x=0$ and $x \geqslant 0.15)$ powders and ceramics at room temperature}

Figure 1(a) shows the X-ray diffraction (XRD) patterns at room temperature of the pure $\mathrm{Na}_{0.5} \mathrm{Bi}_{0.5} \mathrm{TiO}_{3}$ (NBT, $x=0$ ) powders calcined at $950{ }^{\circ} \mathrm{C}$. Figure $1(\mathrm{~b})$ shows the dependence of XRD patterns of $(1-x) \mathrm{NBT}-x \mathrm{CT}$ with increasing the $\mathrm{CT}$ concentration. 


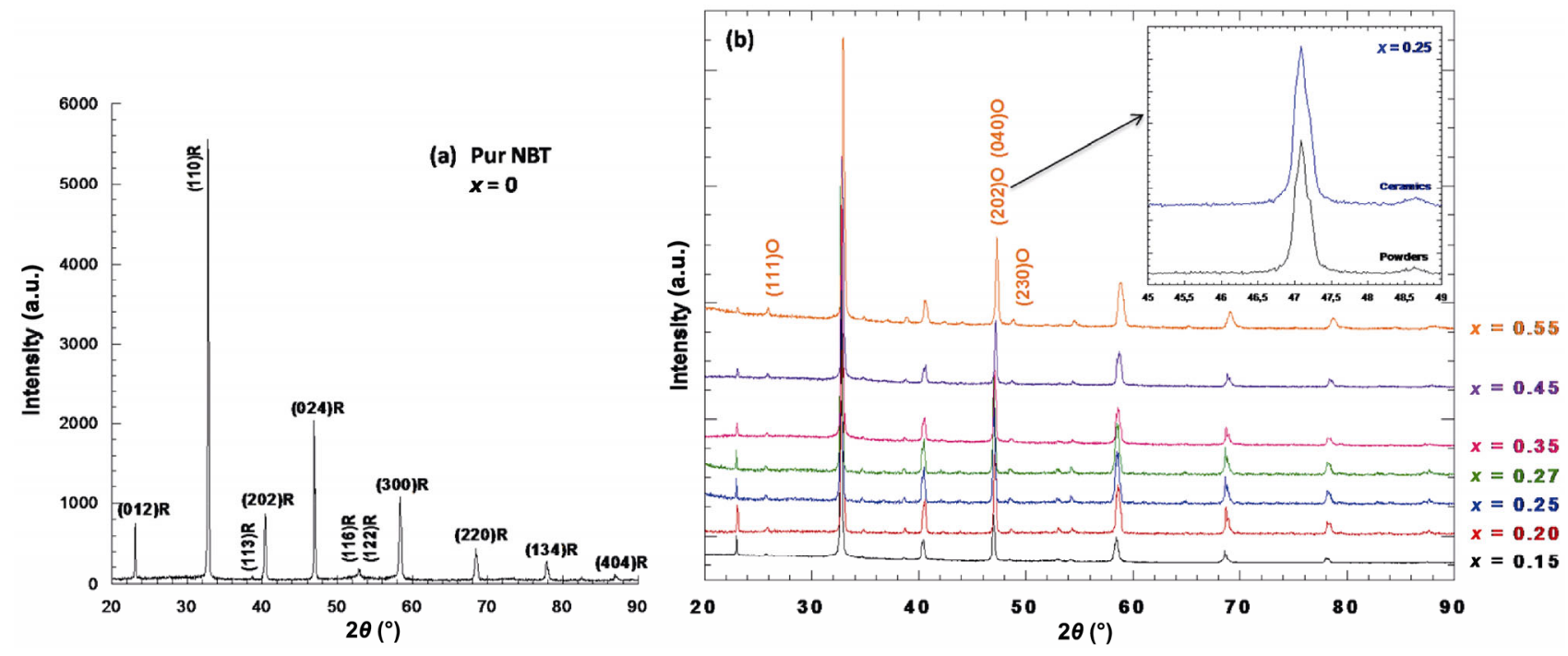

Fig. 1 XRD patterns of (a) NBT $(x=0)$ and (b) $(1-x)$ NBT $-x$ CT $(0.15 \leqslant x \leqslant 0.55)$ at room temperature. The inset in Fig. 1(b) shows the similarity of XRD patterns between powders and ceramics for $x=0.25$ at room temperature.

It is clear from the pattern results that all samples show a single $\mathrm{ABO}_{3}$ perovskite phase with their characteristic peaks and no traces of secondary phase are obtained. This implies that the calcium is completely diffused into the lattice of NBT in order to form a solid solution called $(1-x)$ NBT $-x$ CT (Fig. 1(b)). The rhombohedral characteristic peak $(110)_{\mathrm{R}}$ at about $32^{\circ}$ (Fig. 1(a)) is clearly recorded from the diffractogram of NBT and disappeared as the CT concentration becomes higher than 0.15 . It is evident that the NBT $(x=0)$ exhibits a rhombohedral phase with the space group $(R 3 c)$. It is important to note that the recently reported structure by Aksel et al. [51] for pure NBT at room temperature (obtained by Rietveld refinement) should be monoclinic with space group $C c$ which has a tilting octahedra system $\left(a^{-} a^{-} c^{-}\right)$instead of $R 3 c\left(a^{-} a^{-} a^{-}\right)$. Effectively, their proposed model did not permit to describe the structure obtained in our case (pure NBT) since the peaks $(110)_{\mathrm{pc}}$ and (111) $)_{\mathrm{pc}}$ (indexed with pc: pseudocubic unit cell for $(110)_{\mathrm{R}}$ and $(202)_{\mathrm{R}}$ respectively) are perfectly narrow and symmetric which is not the case of a single phase $C c$. Note that, different refinements were carried out [52] with the different possible structure of NBT at room temperature and the good quality of fit is obtained with $R 3 c$ model since the difference between the theoretical and experimental peaks is relatively small. Recently, Roukos et al. [53] demonstrated the possibility for obtaining the monoclinic phase $(C c)$ under electric field (transition $R 3 c$ to $C c$ ) where the asymmetry completely matched that obtained by Aksel et al. [51]. It is essential to point out that up to now most of the published works highlighted the rhombohedral structure $(R 3 c)$ of pure NBT $[54,55]$. At $x \geqslant 0.15$, we notice the apparition of $(111)_{\mathrm{O}}$ and $(230)_{\mathrm{O}}$ at $2 \theta$ around $26^{\circ}$ and $49^{\circ}$ which is characteristic of the orthorhombic phase with the space group (Pnma). This is very similar to pure CT [56]. Thus the symmetry of the samples changes completely as shown by XRD peaks in Fig. 1(b). When the CT concentration increases $(x \geqslant 0.15)$, the structure is transformed from rhombohedral to orthorhombic symmetry due to the high distortion caused by CT substitution. Inset figure compares the XRD patterns between powders and ceramics for $x=0.25$ of $2 \theta=45^{\circ}-49^{\circ}$ at room temperature. No difference is detected between the two samples. This confirms that all of these samples are completely sintered in pure perovskite phase without inducing any secondary phase of $\mathrm{TiO}_{2}$ due to the high volatility of $\mathrm{Na}$ and $\mathrm{Bi}$ during sintering operation.

\section{2 Dielectric properties of $(1-x)$ NBT-xCT ceramics}

The temperature dependence of the real and imaginary parts of the relative permittivity for pure NBT $(x=0)$ is shown in Fig. 2(a). The dielectric loss tangent $(\tan \delta)$ for $(1-x) \mathrm{NBT}-x \mathrm{CT}$ ceramics is illustrated in Figs. 2(b) and 2(c) at various frequencies $(100 \mathrm{~Hz}-$ $1 \mathrm{MHz}$ ). Phase transitions are all obtained obviously and the peaks become broader with increasing the amount of CT substitution. This is so clear in the imaginary part $\left(\varepsilon^{\prime \prime}\right)$ and loss tangent $(\tan \delta)$. Apparently, the dielectric behaviour of pure NBT $(x=$ 0 ) (Fig. 2(a)) is in agreement with previous studies $[11,57,58]$ showing an anomaly defined as shoulder in 


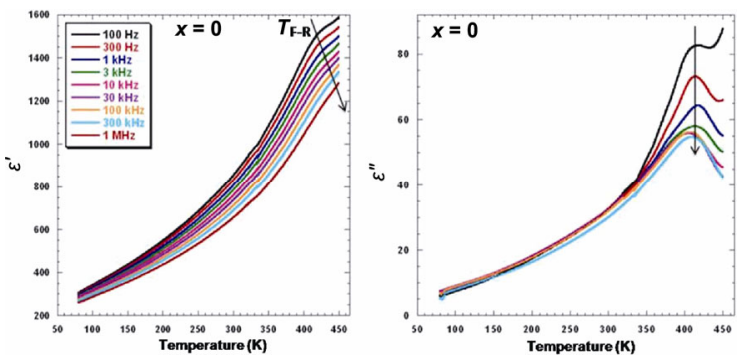

Fig. 2 (a) Evolution of the real part $\left(\varepsilon^{\prime}\right)$ and the imaginary part $\left(\varepsilon^{\prime \prime}\right)$ with temperature at different frequencies of pure NBT $(x=0)$ ceramics.

the $\varepsilon^{\prime}$ at $440 \mathrm{~K}$, named $T_{\mathrm{F}-\mathrm{R}}$. This dielectric anomaly at lower temperature is defined and attributed as the transition from ferroelectric to relaxor state (F-R) $[59,60]$. Below $T_{\mathrm{F}-\mathrm{R}}=440 \mathrm{~K}$, the dielectric constant shows a strong frequency dispersion which is obvious in $\tan \delta$, implying a relaxor ferroelectric behaviour [61]. This was confirmed recently by experimental measurements [19], where the ferroelectric state is stable upon heating until $T_{\mathrm{F}-\mathrm{R}}$ is reached. At this moment, the ferroelectric long range order breaks up and decays, and then the material converts to short range ordered state. Therefore the PNRs are established giving rise to the frequency dispersion at $T_{\mathrm{F}-\mathrm{R}}$. Note that, this anomaly does not involve any phase transition such as ferroelectric-antiferroelectric (denoted depolarization temperature $T_{\mathrm{d}}$ ). Furthermore, the determination of $T_{\mathrm{F}-\mathrm{R}}$ is only valid for poled samples and can be obtained from the frequency independent peak in the dielectric loss $[62,63]$. Recent investigation of the NBT-based relaxor ferroelectrics, such as NBT-BT [60], NBT-KBT-ST [64], and NBT-BT-BZT [62] systems, before and after poling cycling revealed that the phase stability is a relaxor with coexistence of polar nanoregions (PNRs) of different symmetries (rhombohedral+tetragonal). The corresponding mechanism was described at zero field as non-polar phase, i.e., an ergodic relaxor phase [60]. In our case, for pure NBT, the dielectric anomaly obtained at low temperature may be due to the thermal evolution of discrete rhombohedral PNRs which leads to the ferroelectricrelaxor transition state. In analogy with the XRD analysis (Fig. 1(a)), we found out that there is no peak splitting (except for $\mathrm{Cu} \mathrm{K}_{2}$ ) detected at room temperature. Consequently, the absence of any obvious distortion demonstrates that the rhombohedral distortion which is responsible for the obtained dielectric and macroscopic properties is compatible with the very small-scale PNRs over the detection limit of X-ray making them difficult to be visible [62]. Taking into consideration this assumption, an interesting event sequence occurred during heating and cooling. The initial phase $R 3 c$ PNRs undergo a thermal evolution and could easily transform into tetragonal $P 4 \mathrm{bm}$ PNRs with increasing temperature. This was proved by Roukos [52] via in situ Raman spectroscopy where these two phases coexist resulting in an interaction and coherence of dipoles within these PNR domains throughout a wide temperature range. This leads to an anomaly that appears as a broad shoulder frequency dependent.

While increasing $x$ above 0.15 (Fig. 2(b)), the structure is orthorhombic (Pnma). The dielectric behaviour of all samples is completely different from what is obtained for $x=0$. The important substitution in A-site modifies significantly the dielectric characteristics of the material. A strong frequency dispersion of the dielectric constant $\left(\varepsilon^{\prime}, \varepsilon^{\prime \prime}\right)$ and $\tan \delta$ is clearly obtained for all samples. Only one temperature called $T_{\mathrm{m}}$ drastically depends on frequency. This temperature $\left(T_{\mathrm{m}}\right)$-that corresponds to the maximum value of the dielectric constant $\left(\varepsilon^{\prime}\right)$-appears as an anomaly that decreases with the increase of the CT concentration and becomes below room temperature. It is evident that these two characteristics are typical for relaxor. Therefore, it can be concluded that for high concentration of substitution, the variation of dielectric constant and non-polar space group (Pnma) provides a typical relaxor which does not respect the Curie-Weiss law.

A remarkable feature of these series of samples is the strong decrease in the transition temperature $T_{\mathrm{m}}$ when the amount of CT increases as shown in Table 1. At the same time, a significant decrease in $\varepsilon_{\mathrm{m}}$ (maximum dielectric constant) is observed, whereas $\tan \delta_{\mathrm{m}}$ remains practically the same whatever $x$ is. It is also found that for $x=0.15$, the temperature $T_{\mathrm{m}}$ is situated at the vicinity of room temperature. For a substitution less than $0.15, T_{\mathrm{m}}>T_{\mathrm{RT}}$ (RT: room temperature); conversely, for $x>0.15, T_{\mathrm{m}}<T_{\mathrm{RT}}$. This has already been observed experimentally by XRD where the structure is orthorhombic. Moreover, the structural analysis by Rietveld refinement reported by Roukos [52] proved that this sample is located near the morphotropic phase boundary (MPB). Hence the question comes: is the dielectric peak obtained at room temperature for this sample associated to a diffuse phase transition which extends over a wide temperature 

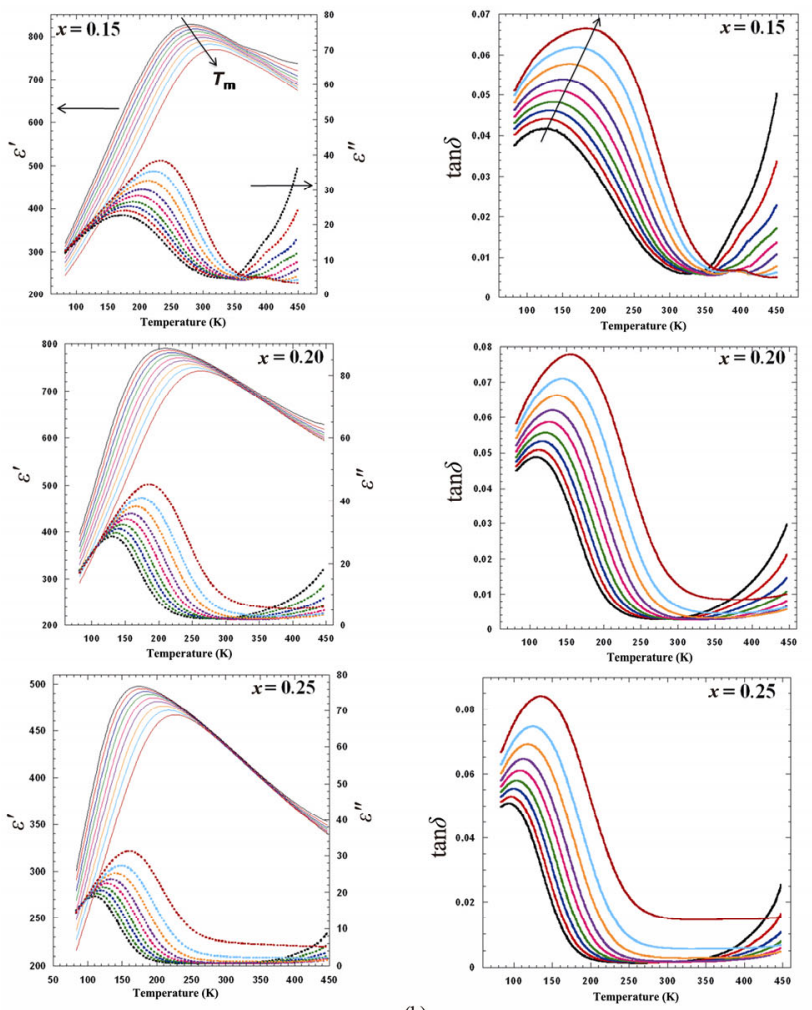
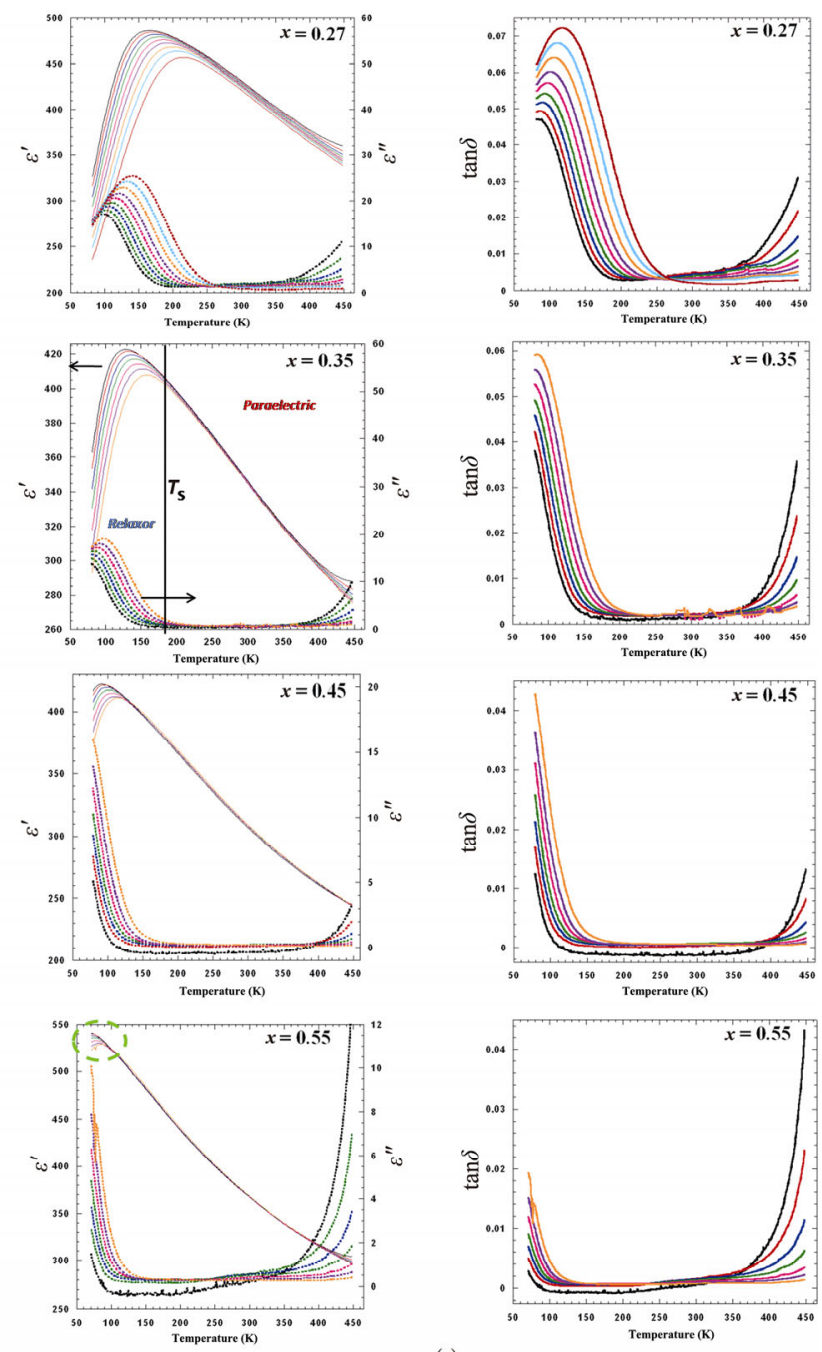

Fig. 2 (b) and (c) Temperature dependence of dielectric constant $\left(\varepsilon^{\prime}\right.$ and $\left.\varepsilon^{\prime \prime}\right)$ and dielectric loss $(\tan \delta)$ of $(1-x)$ NBT $-x \mathrm{CT}$ ceramics where $x=0.15,0.20,0.25,0.27,0.35,0.45$, and 0.55 .

range? Or will it show a relatively abnormal behaviour close to MPB region? [11,65-67].

The variation of different dielectric parameters can be explained by the fact that if a small size of $\mathrm{Ca}^{2+}$ ion

Table 1 Variation of the maximum of dielectric constant $\left(\varepsilon_{\mathrm{m}}\right.$ : real part), the maximum temperature, and the dielectric loss $\left(\tan \delta_{\mathrm{m}}\right)$ for $(1-x) \mathrm{NBT}-x \mathrm{CT}$ ceramics as a function of $x$ at $10 \mathrm{kHz}$

\begin{tabular}{cccc}
\hline$x(\mathrm{CT})$ & $\varepsilon_{\mathrm{m}}$ & $T_{\mathrm{m}}(\mathrm{K})$ & $\tan \delta_{\mathrm{m}}$ \\
\hline 0.15 & 804 & 295 & 0.0509 \\
0.20 & 771 & 231 & 0.0586 \\
0.25 & 485 & 195 & 0.0591 \\
0.27 & 476 & 185 & 0.0570 \\
0.35 & 414 & 146 & 0.0527 \\
0.45 & 416 & 105 & - \\
0.55 & 532 & 73 & - \\
\hline
\end{tabular}

replaces the $\left(\mathrm{Na}^{+}, \mathrm{Bi}^{3+}\right)^{1 / 2}$ in the $(1-x) \mathrm{NBT}-x \mathrm{CT}$ system it decreases $T_{\mathrm{m}}$. The obtained result matches the results of our XRD structural analysis. The A-site substitution in NBT decreases the lattice parameters. Consequently the lattice distortion of NBT reduces which leads to a reduction in $T_{\mathrm{m}}$ sharply towards lower temperature. This is probably due to a transformation from ferroelectric macrodomains of NBT, since it is ferroelectric at room temperature, to a polar nanodomain because of the small ion and low polarizability of $\mathrm{Ca}^{2+}$. Since the orthorhombic phase of CT (Pnma) obtained by XRD for $x \geqslant 0.15$ is centrosymmetric and therefore is not anticipated to show any dielectric peak in the temperature range of this study, this will lead to a decrease in $\varepsilon$ of the system.

Table 1 also shows that $\tan \delta_{\mathrm{m}}$ remains unchanged 
and constant whatever the CT content is. This can be related to the high densification of material with a minimum porosity. This invariable parameter is original in such complex perovskite system where most studies demonstrated that $\tan \delta$ undergoes an important variation due to higher oxygen vacancy concentration $[11,13]$. Besides, $\mathrm{CaTiO}_{3}$ is a paraelectric phase with $\mathrm{Ti}^{4+}$ located in the center of octahedral due to the similar ion state $\mathrm{Ca}^{2+}$ for $\left(\mathrm{Na}_{0.5} \mathrm{Bi}_{0.5}\right)^{2+}$ which does not produce oxygen vacancy. Thus $\tan \delta$ remains stable along with small values independent of CT concentration. This result could be used for low and high temperature application. Similar variations of dielectric properties are often observed in the lead-based solid solution systems such as PMN-PT [68] and more particularly in the lead-free systems like NBT-BT [67], $\mathrm{NBT}-\mathrm{BiCrO}_{3}$ [57], and NBT-BT-KNNBO${ }_{3}$ [69].

\section{3 Study of relaxor behaviour of (1-x)NBT-xCT ceramics for $x \geqslant 0.15$}

From the results obtained in Fig. 2(b), it is observed that increasing the CT concentration enhances the dielectric relaxation which can reach a maximum for high values of $x$.

\subsubsection{Difference between the maximum temperatures $\left(T_{\mathrm{m}}\right)$}

A global way to express the frequency dispersion of $T_{\mathrm{m}}$ can be obtained using a simple empirical relation by calculating $\Delta T$. This parameter is defined as the difference between the temperature $T_{\mathrm{m}}$ for the highest frequency and the one corresponding to the lowest frequency. Moreover, it describes the relaxation strength. This relation is given by

$$
\Delta T_{\text {(real part })}=T_{\mathrm{m}(1 \mathrm{MHz})}-T_{\mathrm{m}(100 \mathrm{~Hz})}
$$

The obtained values of $\Delta T$ are listed in Table 2 .

Table 2 Evolution of the frequency dispersion via $\Delta T$ as a function of $x$ (CT concentration) where $0.15 \leqslant$ $\boldsymbol{x} \leqslant \mathbf{0 . 5 5}$

\begin{tabular}{cc}
\hline$x(\mathrm{CT})$ & $\Delta T \pm 0.5(\mathrm{~K})$ \\
\hline 0.15 & 37 \\
0.20 & 53 \\
0.25 & 53 \\
0.27 & 49 \\
0.35 & 44 \\
0.45 & 45 \\
0.55 & - \\
\hline
\end{tabular}

The results show that the dispersion increases compared to $x=0.15$. In other words, $\Delta T$ increases for the compositions between 0.15 and 0.20 and then remains constant where CT concentration is higher than $x=0.20$. In fact, the minimum dispersion is obtained for $x=0.15(37 \mathrm{~K})$ with a large deviation vis-a-vis other materials. This explains why the dispersion is enhanced by substitution and also proves that all compositions with $x \geqslant 0.15$ exhibit the same dielectric behaviour. Therefore, there is a transformation from ferroelectric material $(x=0)$ to relaxor for higher CT concentration $(x \geqslant 0.15)$.

\subsubsection{Modified Curie-Weiss law}

In order to clarify the dielectric behaviour of all specimens and to highlight the order of diffusivity, a modified Curie-Weiss law is proposed. It describes the reciprocal of the dielectric constant and the diffuseness of a phase transition at large temperature range. It is given by the following relation:

$$
1 / \varepsilon^{\prime}-1 / \varepsilon_{\mathrm{m}}=\left(T-T_{\mathrm{m}}\right)^{\gamma} / C
$$

where $\varepsilon^{\prime}$ is the real part of dielectric constant at a temperature $T, \varepsilon_{\mathrm{m}}$ is the value of dielectric constant at $T_{\mathrm{m}}, C$ is the Curie-Weiss constant, and the parameter $\gamma$ is the degree of diffuseness where its value reflects more or less the diffuse phase transition character in the material. Its value varies between 1 for a normal ferroelectric and 2 for an ideal ferroelectric relaxor.

The value of $\gamma$ is calculated from the fitting results of the plots of $\ln \left(1 / \varepsilon^{\prime}-1 / \varepsilon_{\mathrm{m}}\right)$ as a function of $\ln \left(T-T_{\mathrm{m}}\right)$ for all ceramics at $10 \mathrm{kHz}$. The results are shown in Fig. 3.

A linear relationship is obtained for this series of ceramics. All the fitting results show a high regression coefficient, indicating that the experimental results are higher than 1 , and $\gamma$ values for $x \geqslant 0.15$ ceramics are: $1.53,1.60,1.56,1.57,1.51,1.42$, and 1.38 respectively. Due to the fact that the obtained values of $\gamma$ are relatively large, this clearly confirms that these ceramics are relaxor and this character is the same as whatever the CT concentration is. Note that the intermediate $\gamma$ values show that the present system is different from the ideal relaxor with $\gamma \approx 2$. Effectively, in the $(1-x) \mathrm{NBT}-x \mathrm{CT}$ system, three kinds of ions $\mathrm{Na}^{+}, \mathrm{Bi}^{3+}$, and $\mathrm{Ca}^{2+}$ are randomly distributed in the A-site with 12-fold coordination, so that the relaxor behaviour observed at $T_{\mathrm{m}}$ is related to the coexistence of three ions in the same A-site. Therefore, this behaviour 

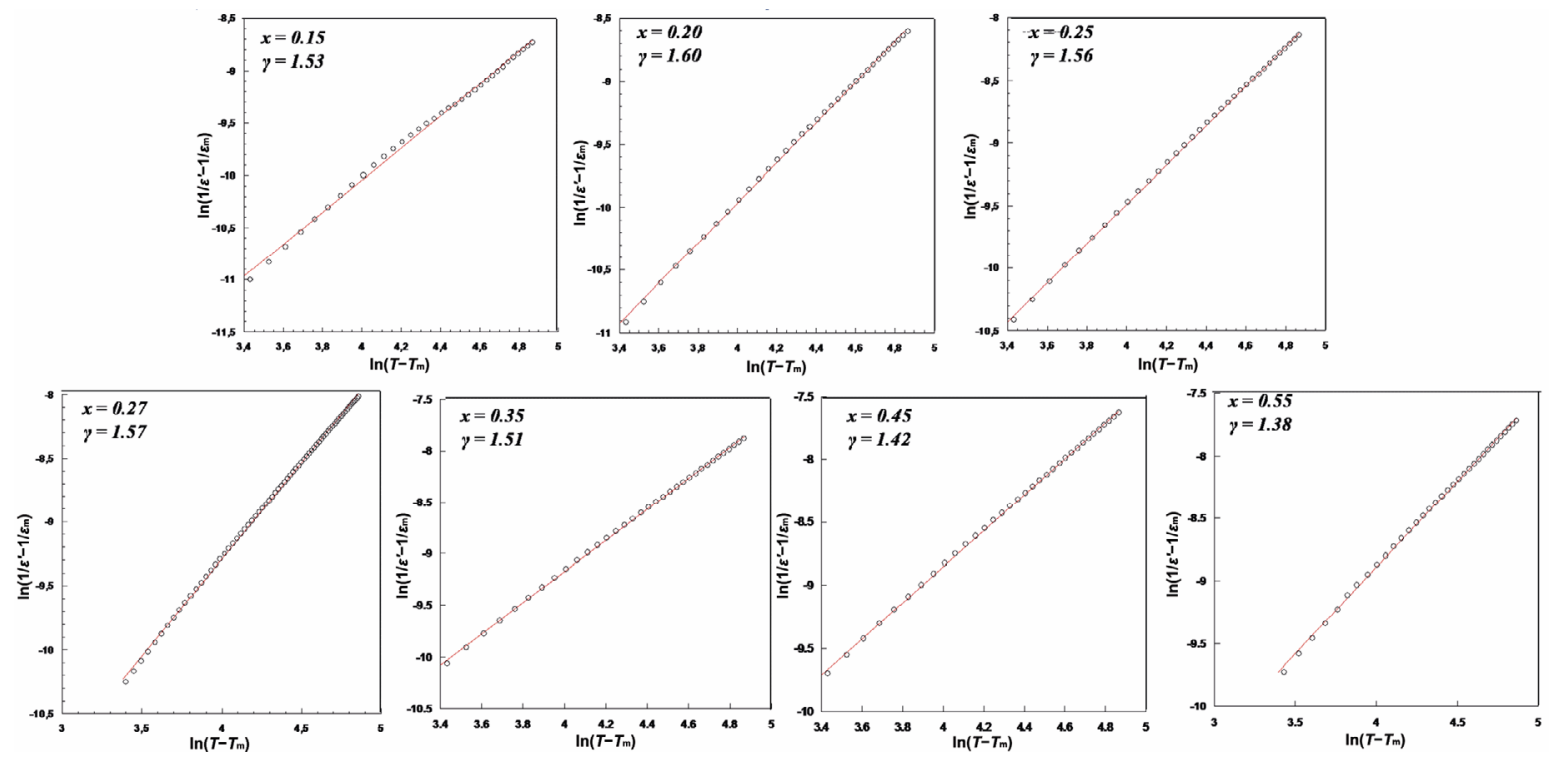

Fig. 3 Plots of $\ln \left(1 / \varepsilon^{\prime}-1 / \varepsilon_{\mathrm{m}}\right)$ as a function of $\ln \left(T-T_{\mathrm{m}}\right)$ of $(1-x) \mathrm{NBT}-x \mathrm{CT}(0.15 \leqslant x \leqslant 0.55)$ at the frequency of 10 $\mathrm{kHz}$. The circle symbols represent the experimental data, while the red solid lines are the fitting curves according to the modified Curie-Weiss law (Eq. (2)).

is attributed to the high cationic disorder of A-site [61,69-71]. XRD analysis confirms this information where low angle XRD analysis for $x=0.25$ ceramic showed no peak of superstructure [52].

\subsubsection{Vogel-Fulcher relationship}

In the $(1-x) \mathrm{NBT}-x \mathrm{CT}$ system, an Arrhenius law cannot correctly describe the evolution of $T_{\mathrm{m}}$ with frequency. The $\log f$ as a function of $1 / T_{\mathrm{m}}$ curves cannot be fitted with an Arrhenius law and the fitting does not correspond to the experimental points. For this reason, Vogel-Fulcher relation was used to describe the nature of dielectric relaxation [72]. It relates the frequency dispersion and the temperature $T_{\mathrm{m}}$ of the maximum dielectric permittivity by the activation energy $E_{\mathrm{a}}$ (defined as the barrier between two equivalent polarization states). It is expressed by the following relation:

$$
f=f_{0} \exp \left(-\frac{E_{\mathrm{a}}}{k_{\mathrm{B}}\left(T_{\mathrm{m}}-T_{\mathrm{vf}}\right)}\right)
$$

where $f$ is the operating frequency, $f_{0}$ is the attempt frequency, $E_{\mathrm{a}}$ is the activation energy for relaxing dipoles, $k_{\mathrm{B}}$ is the Boltzmann constant, and $T_{\mathrm{vf}}$ is the freezing temperature related to relaxation dynamics. Figure 4 shows the fitting curves by Vogel-Fulcher relationship between $\log f$ (frequency: $100 \mathrm{~Hz}-1$ $\mathrm{MHz})$ and $1 /\left(T_{\mathrm{m}}-T_{\mathrm{vf}}\right)$ for all ceramics $(x \geqslant 0.15)$. The results obtained exhibit an excellent fitting and a good approximation of the experimental data with the proposed model (solid line). This confirms that the Vogel-Fulcher relationship can be used to study the relaxation behaviour for higher $\mathrm{CT}$ concentration.

The evolution of the activation energy $\left(E_{\mathrm{a}}\right)$ and the freezing temperature $\left(T_{\mathrm{vf}}\right)$ as a function of CT concentration are reported in Table 3. It is found that the activation energy increases reaching a constant level where $E_{\mathrm{a}}$ has approximately the same value for higher CT concentrations. The particularly high $E_{\mathrm{a}}$

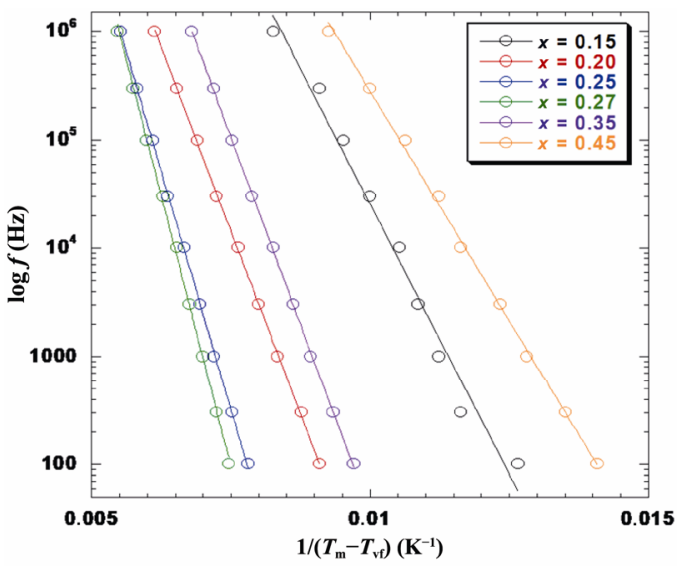

Fig. 4 Plots of $\log f$ as a function on $1 /\left(T_{\mathrm{m}}-T_{\mathrm{vf}}\right)$ of $(1-x) \mathrm{NBT}-x \mathrm{CT}$ ceramics $(x=0.15,0.20,0.25,0.27,0.35$, and 0.45$)$ verifying Vogel-Fulcher relationship. The circle symbols are the experimental data and lines are corresponding to Eq. (3). 
Table 3 Evolution of the activation energy $\left(E_{\mathrm{a}}\right)$ and the temperature $T_{\mathrm{vf}}$ of the Vogel-Fulcher relationship calculated from $\varepsilon^{\prime}$ as a function of $x$

\begin{tabular}{ccc}
\hline$x(\mathrm{CT})$ & $E_{\mathrm{a}}(\mathrm{eV})$ & $T_{\mathrm{vf}} \pm 0.5(\mathrm{~K})$ \\
\hline 0.15 & 0.20 & 200 \\
0.20 & 0.24 & 100 \\
0.25 & 0.35 & 45 \\
0.27 & 0.28 & 40 \\
0.35 & 0.26 & 25 \\
0.45 & 0.25 & 20 \\
\hline
\end{tabular}

value, obtained for $x=0.25$, is probably due to stoichiometric defects. On the other side, the freezing temperature strongly decreases down to almost $20 \mathrm{~K}$ ( $200 \mathrm{~K}$ for $x=0.15$ ). This decrease can be related to the grain size which depends on $T_{\mathrm{vf}}$ [73], i.e., this effect could be caused by narrowing the volume of polar nanoregions (PNRs). The grain size smaller than PNRs cannot exist; therefore, the volume distribution of PNRs is reduced with grain size [73]. A such diminution of grain size is obtained by Roukos [52], where increasing the $\mathrm{CT}$ concentration leads to a decrease in the grain

size. Consequently, a progressive transformation from Vogel-Fulcher law towards the Arrhenius law in the $(1-x) \mathrm{NBT}-x \mathrm{CT}$ where $T_{\mathrm{vf}}=0 \mathrm{~K}$ will be expected.

Therefore, these results allow adopting the VogelFulcher model to explain the obtained dielectric response, which provides the evidence of the relaxor behaviour in the $(1-x) \mathrm{NBT}-x \mathrm{CT}$ system.

\section{4 Dielectric properties of $(1-x)$ NBT-xCT $(x=0.20)$ as a function of frequency}

Figures 5(a) and 5(b) show the variation of $\varepsilon^{\prime}$ and $\tan \delta$ of the dielectric constant as a function of frequency at different temperatures of $x=0.20$. Both $\varepsilon^{\prime}$ and $\tan \delta$ show a strong dispersion at low frequency which strongly depends on temperature. It is observed that $\varepsilon^{\prime}$ exhibits a large dispersion which linearly decreases with an increase in frequency at lower temperature below $150 \mathrm{~K}$. In contrast, $\tan \delta$ increases with frequency. When the temperature reaches $\sim 200 \mathrm{~K}$ and below $300 \mathrm{~K}$, the dispersion decreases at low frequency. It gradually disappears and exhibits broadness (broad peak as shoulder). In this temperature range $(200 \mathrm{~K} \leqslant T \leqslant 300 \mathrm{~K})$, the broad anomaly shifts gradually towards high frequency with an increase in the temperature and moves out of the specified spectral range which is the typical signature of relaxor behaviour. This observation is stronger in $\tan \delta$ than the real part $\left(\varepsilon^{\prime}\right)$ (Fig. 5(b)). Above room temperature $\geqslant 300 \mathrm{~K}$, the dispersion completely disappears showing the same values whatever the measurement frequency is.

At low temperature, there is a drastically decrease with frequency due to the change of ions moving from long distance to short distance at high frequency, where the ions will be confined into their ion potential wells and can occur only in a local motion (high frequency) [61,74]. In the temperature range of 200$300 \mathrm{~K}$, the observed shoulder appears to be shifting towards high frequency side when the temperature
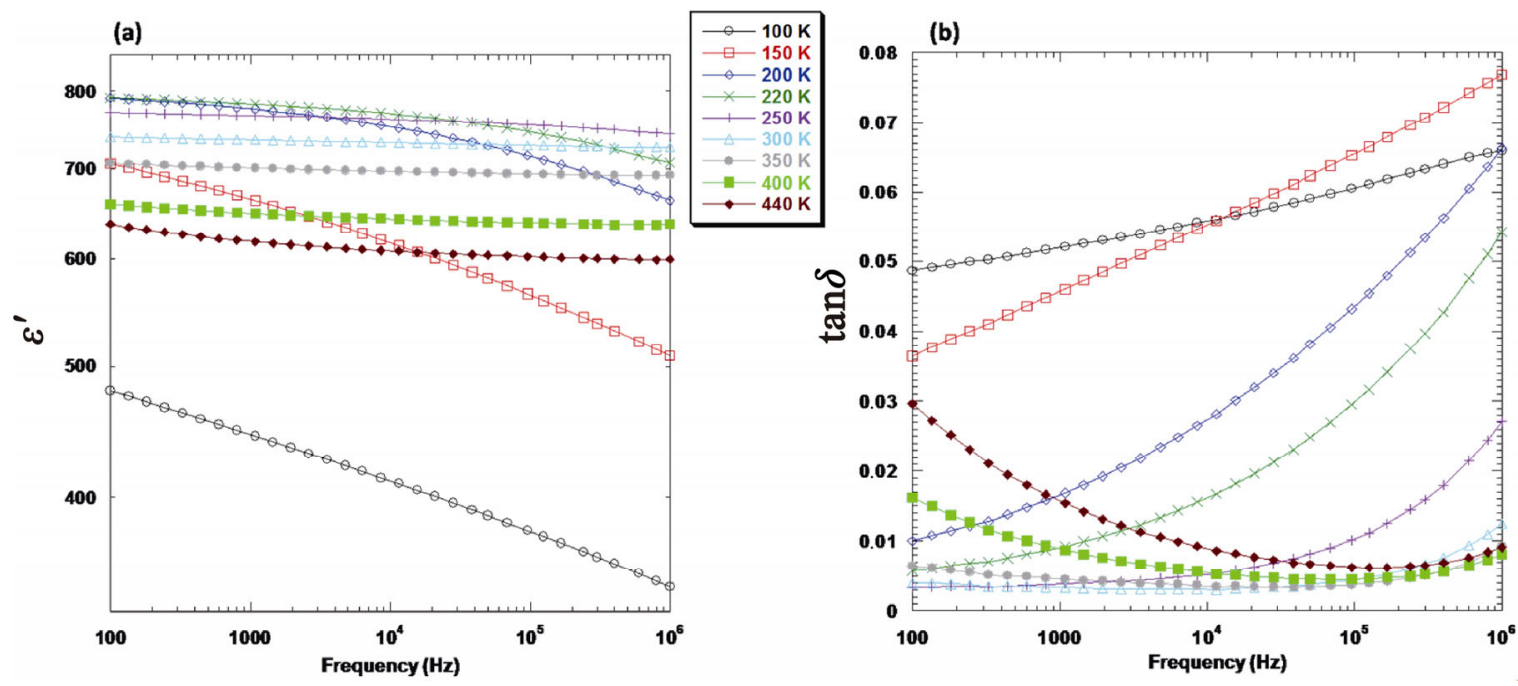

Fig. 5 Variations of (a) dielectric constant $\left(\varepsilon^{\prime}\right)$ and (b) dielectric loss $(\tan \delta)$ as a function of frequency at different temperature for $(1-x) \mathrm{NBT}-x \mathrm{CT}(x=0.20)$. 
increases. This may be due to the distribution of relaxation time in the materials $[71,75]$ indicating the contribution of the polar nanoregions to the total dielectric permittivity of $(1-x) \mathrm{NBT}-x \mathrm{CT}$ where $x \geqslant$ 0.15 .

A remarkable feature of this system is that all transitions and physical phenomena take place at very low temperature specifically below room temperature. With increasing the temperature, it is found that the dielectric constant remains practically constant and independent of frequency. This frequency dispersion dissipates completely, and thereby, the relaxor behaviour disappears from a limit temperature called "threshold temperature $T_{\mathrm{s}}$ ". The corresponding values are presented in Table 4. This temperature strongly decreases with $x$ which shows the same behaviour to that of $T_{\mathrm{m}}$. For $T>T_{\mathrm{s}}$, the curves of the dielectric constant (Fig. 2) are matching together at various frequencies, leading to a normal paraelectric behaviour. This behaviour was confirmed by the deviation of the Curie-Weiss law where $\gamma$ (diffusivity) was found to be around 1.5 (Fig. 3).

From these results and these variations in the dielectric constant of these samples as a function of temperature, it can be seen that these ceramics show a transition from high frequency dependent relaxor to a normal paraelectric phase at high temperature. Hence, it is interesting to know if this variation of dielectric behaviour is accompanied by a structural change. Thus the structural and phase transition are studied by Raman spectroscopy as a function of temperature.

\section{5 Raman spectroscopy studies}

\subsubsection{At room temperature}

In order to complement the XRD results and further show the phase transition performance of all compositions, the Raman spectroscopy of $(1-x) \mathrm{NBT}-x \mathrm{CT}$ was carried

Table 4 Variation of the threshold temperature $T_{\mathrm{s}}$ as a function of $x$

\begin{tabular}{cc}
\hline$x(\mathrm{CT})$ & $T_{\mathrm{s}} \pm 0.5(\mathrm{~K})$ \\
\hline 0.15 & 325 \\
0.20 & 261 \\
0.25 & 225 \\
0.27 & 215 \\
0.35 & 176 \\
0.45 & 135 \\
0.55 & 103 \\
\hline
\end{tabular}

out at room temperature as illustrated in Fig. 6. Figure 6(a) shows the Raman spectra of NBT at room temperature in the wavenumber range of $4-700 \mathrm{~cm}^{-1}$. The spectrum of NBT is in general very similar and in good agreement with the already published work [11,76-79], where it was assigned a total of 13 Ramanactive modes $\left(\Gamma_{\mathrm{R} 3 \mathrm{c}}=4 \mathrm{~A}_{1}+9 \mathrm{E}\right)[78]$ that similar main regions in the spectrum can be detected [79]. It can be seen that all Raman bands are relatively broad which can be related to a possible disorder at A-site due to the random distribution of $\mathrm{Na} / \mathrm{Bi}$ cations. This was clearly reported by Bai et al. [79] in ternary system. There is also an overlap of Raman modes especially at high frequency. At room temperature, the NBT phase shows 5 characteristic bands which are located at 25 (A), 138 (B), 286 (C), 530, and 584 (D) $\mathrm{cm}^{-1}$. Due to the high
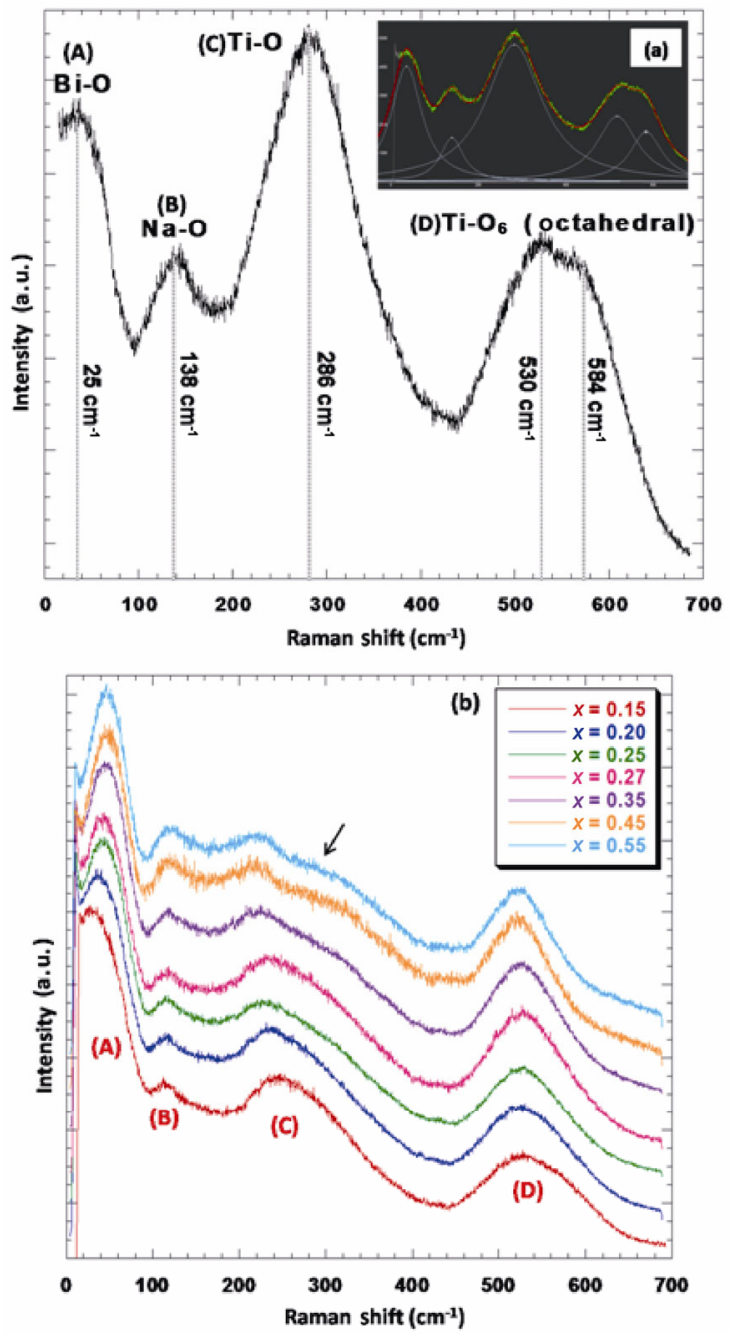

Fig. 6 Raman spectra of (a) pure NBT $(x=0)$ (inset: the spectral deconvolution according to five GaussianLorentzian modes line shape) and (b) $(1-x) \mathrm{NBT}-x \mathrm{CT}$ ceramic system $(0.15 \leqslant x \leqslant 0.55)$ at room temperature. 
molar mass of $\mathrm{Bi}\left(m_{\mathrm{Bi}}=208.98 \mathrm{~g} \cdot \mathrm{mol}^{-1}\right)$, the mode at low frequency $25 \mathrm{~cm}^{-1}$ is associated with $\mathrm{Bi}-\mathrm{O}$ vibration. The band at $138 \mathrm{~cm}^{-1}$ is affected by the vibration of the $\mathrm{Na}-\mathrm{O}$ bond, while the broad band centered at $286 \mathrm{~cm}^{-1}$ is attributed to Ti-O vibration. The modes that appear as an overlapping of two bands at high frequency (D) are essentially assigned to the vibration of the $\mathrm{TiO}_{6}$ octahedra. The inset of Fig. 6(a) shows the spectral deconvolution (fit) by Lorentzian and Gaussian function for pure NBT at room temperature.

The Raman spectra of $(1-x) \mathrm{NBT}-x \mathrm{CT}$ ceramics at room temperature are presented in Fig. 6(b). Several qualitative modifications can be discerned. Most of bands show and undergo shifting and broadening with increasing CT concentration. The broad band at region (B) $138 \mathrm{~cm}^{-1}$ decreases in intensity and moves towards the low frequency $\left(116 \mathrm{~cm}^{-1}\right.$ for $\left.x=0.55\right)$. It becomes sharply narrow and more symmetric for higher CT concentration. The band (C) at $286 \mathrm{~cm}^{-1}$ undergoes a sharp change for $x=0.15$ becoming asymmetric and shifts to lower frequency $\left(210 \mathrm{~cm}^{-1}\right.$ for $\left.x=0.35\right)$. Its intensity strongly decreases with $x$ and may finally tend to disappear. Moreover, an additional mode indicated by an arrow starts to appear as a shoulder where this mode is characteristic of $\mathrm{CaTiO}_{3}(\mathrm{CT})$ phase which is directly included in the phase transition. The band $\mathrm{D}$ around $400-600 \mathrm{~cm}^{-1}$ characteristic of $\mathrm{TiO}_{6}$ octahedra consists of 2 overlapping modes (530 and $\left.584 \mathrm{~cm}^{-1}\right)$. The two modes merged into a single peak for $x \geqslant 0.15$, which becomes symmetric and its intensity gradually increases starting from $x=0.20$. This merging indicates an obvious phase transition and the $\mathrm{Ti}^{4+}$ is more located into the center of the octahedral where the material becomes centrosymmetric. Finally, the band (A) at low frequency $\left(25 \mathrm{~cm}^{-1}\right)$ shows a

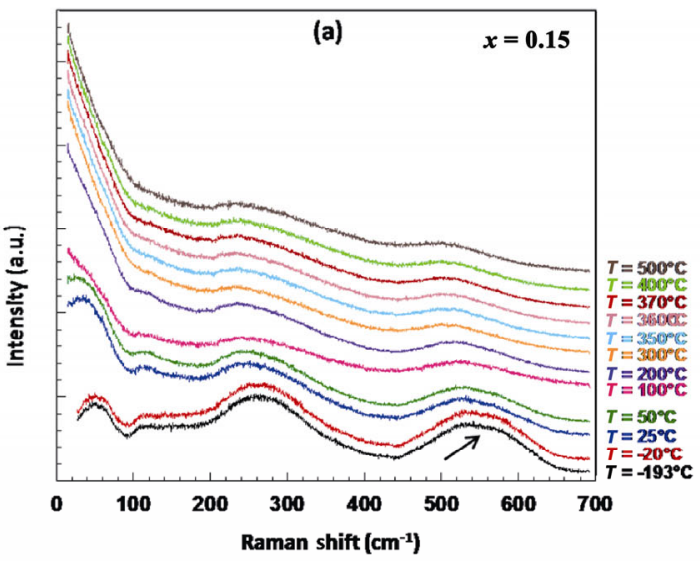

remarkable change. It becomes narrower, symmetrical, and shifts to high frequency $\left(50 \mathrm{~cm}^{-1}\right.$ for $\left.x=0.55\right)$. This is in agreement with the results obtained from $\mathrm{XRD}$ at room temperature (see Section 3.1) with the fact that the Raman spectra in this study are strongly affected by such high concentration of CT.

\subsubsection{At various temperatures}

Figure 7 shows Raman spectra collected as a function of temperature from -193 to $500{ }^{\circ} \mathrm{C}$ for $x=0.15$ and $x=0.20$. While heating, some modes shift and become broad for all compositions. The modes in the regions $\mathrm{A}$ and $\mathrm{B}$ gradually decrease and then disappear at high temperature.

For a better identification of phase transition, the spectra were also fitted with Lorentzian function at different temperatures (Fig. 8).

An unexpected behaviour is observed in the presence of temperature for $x=0.15$ (Fig. 8(a)). In fact, a splitting of the band (D) at low temperature $T \approx$ $-20{ }^{\circ} \mathrm{C}$ to an overlapping of two modes, and an anomaly at high temperature $T=360{ }^{\circ} \mathrm{C}$ are obtained (Fig. 7(a)). These anomalies also appear in the region (C) as discontinuities of the evolution of the frequency and FWMH that exhibit a dramatic change in the phonon behaviour. This band becomes symmetrical and more intense at low temperature (Fig. 7(a)). The comparison of Raman spectra $(x=0.15)$ at low temperature with NBT spectra at room temperature, shows that they are identical. A splitting of the $\mathrm{TiO}_{6}$ octahedra vibration mode occurs by the regeneration of LO (longitudinal optical) and TO (transverse optical) modes respectively, characteristic of pure NBT $(x=0)$. The obtained results reveal a change in symmetry which is attributed to the transition from the orthorhombic

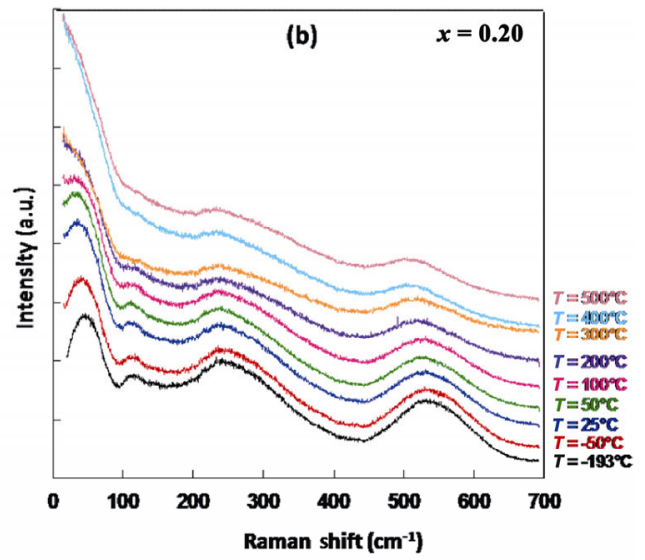

Fig. 7 Raman spectra of $(1-x) \mathrm{NBT}-x \mathrm{CT}$ for (a) $x=0.15$ and (b) $x=0.20$ at various temperature from -193 to $500{ }^{\circ} \mathrm{C}$. 

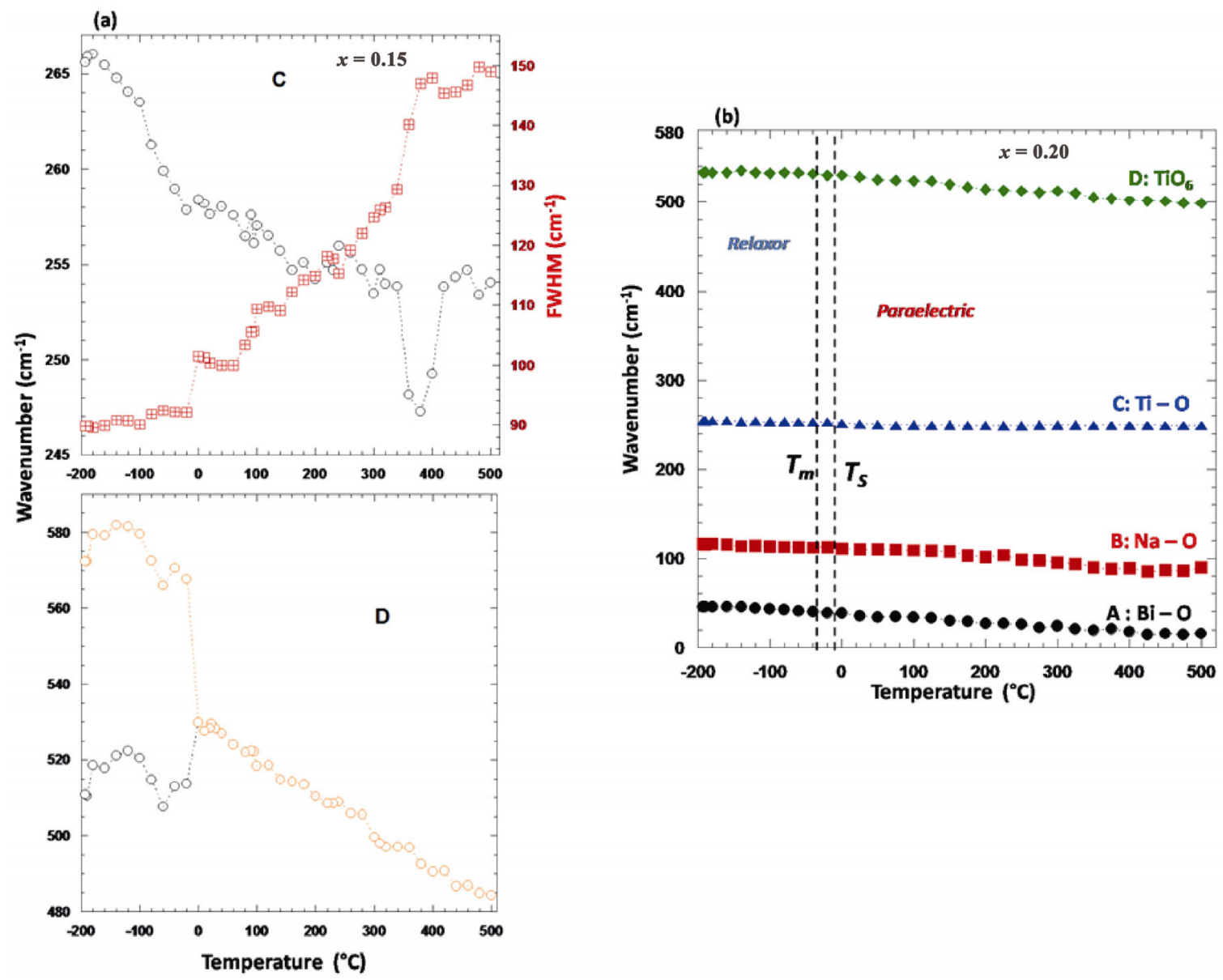

Fig. 8 Evolution of the wavenumber in some strong modes as a function of temperature for (a) $x=0.15\left(\mathrm{C}\right.$ : $\mathrm{Ti}-\mathrm{O}$ and $\mathrm{D}$ : $\left.\mathrm{TiO}_{6}\right)$ and (b) $x=0.20(\mathrm{~A}: \mathrm{Bi}-\mathrm{O}, \mathrm{B}: \mathrm{Na}-\mathrm{O})$.

phase (Pnma) at room temperature to the rhombohedral phase at low temperature $(R 3 \mathrm{c}$ : apparition of local regions). These local regions $(R 3 c)$ will increase during cooling. This is reflected by the increase in the Raman peak intensities at low temperature (Fig. 7(a)). The temperature notably affects the two regions $(\mathrm{C}$ and $\mathrm{D})$ that are directly related to the phase transition since the ferroelectric properties reside in these bands. On the other side, the new anomaly at $T=360{ }^{\circ} \mathrm{C}$ is probably related to the coexistence of the orthorhombic and cubic phases $(\mathrm{O}+\mathrm{C})$, since the transition temperatures decrease and shift to low values with increasing $x$ (CT concentration). As the temperature increases, the mode FWHM at region $\mathrm{C}$ increases indicating a higher disorder in the lattice.

Based on these changes, a rhombohedral low temperature phase is detected, leading to a change in the polar character and the behaviour of the studied material. Although the XRD study shows an orthorhombic structure at room temperature, a relaxor behaviour is obtained and highlighted in the dielectric properties $\left(T_{\mathrm{m}} \leqslant T_{\text {ambient }}\right)$. However, on a local scale, the relaxor is characterized by a particular microstructure with polar regions of reduced sizes $(\mathrm{nm})$ with a particular symmetry $R 3 c$ like the case of PMN $[34,80]$. The origin of this evolution was suggested to appear from the possible formation of nanodomains, i.e., the variation in the size and dynamics of the polar nanoregions (PNRs) [81]. This has been also highlighted by Schütz et al. [82] where this transition is related to the fluctuation of nanoregions which is proven clearly by the temperature dependence of the B-site (Ti-O) and the octahedral modes, the same regions (C and $\mathrm{D})$ in our case. Since the Ti-O (region C) bonds and the octahedral vibrations (region D) are influenced by the dynamics of the nanodomain phase [82], this behaviour is compatible with our materials. In the present system, the incorporation of CT (in A-site) resulted in the decrease of the polarizability of the unit cell, which probably led to a formation of PNRs. This is very 
obvious with the variation of the wavenumber and FWHM where an abrupt discontinuity is obtained near the phase transition at $T \approx 20{ }^{\circ} \mathrm{C}$. Hence, this behaviour is in compatible with the general macroscopic relaxor behaviour obtained by dielectric measurements (Fig. 2). It is essential to point out that such distortion occurs at small scales, i.e., short atomic distances, below the detection limit of XRD. The transition is only local in a non-polar orthorhombic matrix. Note that this transition temperature does not correspond to $T_{\mathrm{m}}$ $(295 \mathrm{~K})$ of the dielectric dispersion and the variations of the phonon behaviour demonstrate that the change in symmetry occurs at temperature below $T_{\mathrm{m}}$. At $T_{\mathrm{m}} \leqslant$ $T \leqslant 360{ }^{\circ} \mathrm{C}$, the Raman band is found to be similar to those of $(1-x) \mathrm{NBT}-x \mathrm{CT}(x \geqslant 0.20)$ at room temperature; thereby, the symmetry is identical above $T_{\mathrm{m}}$.

For $x=0.20$ (Fig. 8(b)), the present Raman spectra do not show any splitting of the bands or any change for all temperature range. The spectra remained unchanged except for small shifting of bands due to heating. The non-appearance of any additional mode or any change in the phonon behaviour reveals that the symmetry of material remains unchanged, and thereby, the orthorhombic structure is stable whatever the temperature is. Such a behaviour is proved with the same number of Raman active modes in the temperature range of $-193-500{ }^{\circ} \mathrm{C}$ and by differential scanning calorimetry (DSC) analysis [52] where the results show that there is no signal indicating a phase transition as a function of temperature. Therefore, the material keeps its structure whatever the temperature is. From a dielectric point of view, this sample exhibits an anomaly attributed to a relaxor behaviour. With further heating, the dielectric behaviour completely changes from relaxor state to paraelectric state. This transition is obtained without a structural change; the structure is orthorhombic (Pnma) in the temperature range of $-193-500{ }^{\circ} \mathrm{C}$. Note that, all samples $(x=0.25,0.27$, $0.35,0.45,0.55)$ in this region give the same results by Raman study as a function of temperature.

It is obvious that, at room temperature the two samples $x=0.15$ and 0.20 have identical structures and show the same dielectric properties. Hence, a question arises here: why do the vibrational properties by Raman spectroscopy, which is considered sensitive to the study of the phase transitions, show different results despite the similarity between these two components? It is important to state that the ceramic $x=0.15$ is situated in the vicinity and near the MPB composition [52] of the (1-x)NBT- $x$ CT system which exhibits a maximum permittivity lower than that at room temperature. Considering these two situations, the hypothesis of a possibility of a rhombohedral phase transition at low temperature is verified.

Thereby, we are considering, at least initially, two possible explanations for these observations:

The difference between the two ceramics $(x=0.15$ and 0.20 ) is related to a structural original. It is probably due to the fact that this solid solution $(x=$ 0.15 ) is found to be near the morphotropic phase boundary (MPB) [52] where the rhombohedral and orthorhombic phases coexist. This MPB is revealed to be effective for the piezoelectric properties [83]. The majority of complex systems with this boundary have excellent properties such as: improvement of dielectric behaviour which becomes higher than usual $[7,67]$. It was shown that these systems may also display an unusual and strange structural behaviour $[3,84,85]$ which is the case of our system where $x=0.15$.

On the other side, it may be due to the presence of small fraction of the rhombohedral $(R 3 c)$ phase merged into the orthorhombic phase as a matrix, where their dimensions ( $\mathrm{nm}$ and/or $\mu \mathrm{m}$ ) become smaller than the coherence length of the X-rays at room temperature, and therefore they are not clearly detected. However, this transformation can be ascertained as a growth of these rhombohedral regions, which becomes more and more detectable at low temperature. Such transition is observed and is in good agreement with the PMN relaxor $[30,33,34]$. In this paper, the results prove that the CT concentration increase divides the ferroelectric macrodomains into polar micro and/or nanodomains, which consequently is responsible of the relaxor behaviour encountered here.

After comparing the dielectric results with Raman spectroscopy, we notice that the relaxor behaviour takes place thanks to the PNRs which start to increase and grow with decreasing temperature due to the local phase transition (phonon behaviour). The dielectric dispersion obtained around $T_{\mathrm{m}}$ is described as an interaction among the PNRs which becomes stronger with temperature decrease. An additional cooling stops the PNRs growth at a limiting temperature, called freezing temperature $\left(T_{\mathrm{vf}}\right)$. This was verified by Vogel-Fulcher relation where a good fit was obtained for these series of samples.

Based on the different results obtained for $x \geqslant$ 0.15 (high concentration of CT), the relaxor behaviour 
may occur for many reasons such as structural distortion which is related to the compositional fluctuation or structural disorder in the arrangements of cations in A-site. In the case of $(1-x) \mathrm{NBT}-x \mathrm{CT}$, A-site is occupied by $\mathrm{Ca}^{2+}\left(r_{\mathrm{Ca}^{2+}}=1.34 \AA\right)$ for a coordination number equal to 12 . Therefore, the relaxor behaviour may be attributed to the cationic disorder induced by the A-site substitution and the presence of three cations in the same site. The observed parameters of diffusivity $(\gamma)$ are high and stable till $x=0.45$ and then decrease immediately as CT concentration exceeds $x=0.55$ as shown in Fig. 3. This could be due to a cationic order in A-site where the composition fluctuation is minimized. Theoretically, it is known that, if the ionic radius difference at A-site is high, it enhances the ordering degree and consequently the decrease in compositional fluctuations according to Viehland et al. [86]. In the case of $(1-x) \mathrm{NBT}-x \mathrm{CT}$ system, the difference in ionic radii at A-site is very close and small which could be responsible for a high value of diffusivity parameters $(\gamma)$. Therefore, this relaxor behaviour may be attributed to the disorder of $\mathrm{Na}^{+} / \mathrm{Bi}^{3+} / \mathrm{Ca}^{2+}$ cations in A-site crystallography. Furthermore, when $\left(\mathrm{Na}^{+}, \mathrm{Bi}^{3+}\right)^{1 / 2}$ is substituted by $\mathrm{Ca}^{2+}$, it seems that $\mathrm{Ca}^{2+}$ destabilizes the ferroelectric properties of NBT and improves the paraelectric behaviour due to its lower polarizability which destroys the octahedral properties responsible for ferroelectric character, and to the small ionic radii of $\mathrm{Ca}^{2+}$. In this case the long range order, if exists in NBT, will break up and turn into micro and/or nanosmall range order which will probably cause a relaxor behaviour.

In summary, all the results obtained in this concentration range of $\mathrm{CT}$ show that in the solid solution $(1-x) \mathrm{NBT}-x \mathrm{CT}$, the ferroelectric behaviour for $x=0$ disappears completely during the substitution. For high CT concentration, the relaxor behaviour becomes more remarkable: ferroelectric $(x=0) \rightarrow$ relaxor $(x=0.15)$. The relaxation analysis was validated by the Vogel-Fulcher relationship; the values of the activation energy give an idea of the origin of this effect. The variation of the dispersion, the activation energy $E_{\mathrm{a}}$, and the temperature of the gel $T_{\mathrm{vf}}$ are directly related to the high concentration of CT. In fact, the A-site of the perovskite structure is occupied by three cations: $\mathrm{Na}^{+} / \mathrm{Bi}^{3+} / \mathrm{Ca}^{2+}$, and their valences and their atomic radii are relatively different. This may cause a random distribution of these cations at A-site, and consequently a cationic disorder. In addition, it is very known that the CT is no-ferroelectric (orthorhombic-paraelectric phase found by XRD analysis) at room temperature, because the $\mathrm{Ti}^{4+}$ cation is located in the central equilibrium position of the CT unit cell. The variation of $E_{\mathrm{a}}$ and $T_{\mathrm{vf}}$ shows that the CT substitution destroys the ferroelectric character and gradually induces the relaxor state. As a result, the ferroelectric macrodomains of NBT $(x=0)$ are divided into polar micro- and nanodomains with increasing $x$ resulting in the appearance of the relaxor behaviour. This was validated by Raman measurements as a function of temperature on ceramic $x=0.15$, where a splitting of the vibration mode $\mathrm{TiO}_{6}$ octahedra and regeneration of two modes $\mathrm{LO}$ and $\mathrm{TO}$ characteristic of pure NBT were observed. The obtained transition is therefore attributed to the appearance of polar nanoregions with $(R 3 c)$ symmetry into a non-polar orthorhombic matrix (Pnma) which is, in fact, responsible for the relaxor behaviour.

\section{6 Binary phase diagram of $(1-x)$ NBT-xCT ceramics system}

Figure 9 summarizes the phase transition temperatures $T_{\mathrm{m}}$ and $T_{\mathrm{s}}$ identified by the dielectric properties as well as the different phases obtained by X-ray and Raman analysis for $(1-x) \mathrm{NBT}-x \mathrm{CT}$ system. $T_{\mathrm{m}}$ and $T_{\mathrm{s}}$ exponentially decrease as $x$ increases. The magnitude of decreasing $T_{\mathrm{m}}$ and $T_{\mathrm{s}}$ is almost the same and their curves start from room temperature $\left(T_{\mathrm{m}}\right)$ for $x=0.15$ and reach very low temperature $73 \mathrm{~K}$ for $x=0.55$. In analogy with other systems $[11,57,87]$, a binary phase diagram is proposed for the $(1-x) \mathrm{NBT}-x \mathrm{CT}$ system for a high concentration of CT $(0.15 \leqslant x \leqslant 0.55)$. The indicators used in this diagram are: $T<T_{\mathrm{m}}, T_{\mathrm{m}}<T_{\mathrm{s}}$, and $T>T_{\mathrm{s}}$ designed by three regions $\mathrm{A}, \mathrm{B}$, and $\mathrm{C}$ respectively consist of three phases shown in Fig. 9. From XRD results and structural investigation, it can be seen that the regions $\mathrm{A}$ and $\mathrm{B}$ have an orthorhombic structure with Pnma as space group and also show a relaxor behaviour. The region $\mathrm{C}$ possesses an orthorhombic structure (Pnma) which is the same structure as in the regions $\mathrm{A}$ and $\mathrm{B}$ but shows a different dielectric behaviour where the relaxor disappears and the materials become paraelectric in this temperature range. It can be concluded that no structural phase transition is obtained, in which the solids pass from a relaxor state to a paraelectric state while retaining the same crystal structure. 


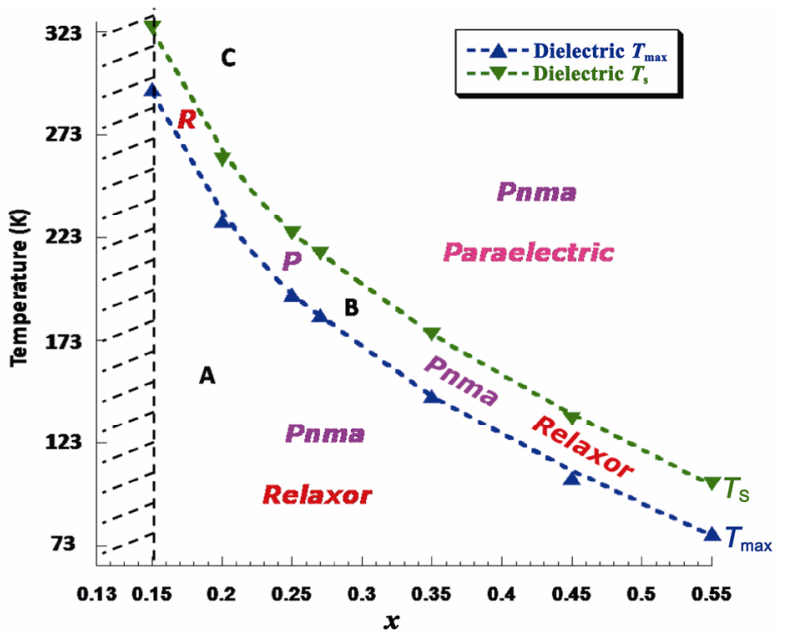

Fig. 9 Binary phase temperature-composition diagram of the $(1-x)$ NBT $-x \mathrm{CT}$ system determined by dielectric properties $\left(T_{\mathrm{m}}\right.$ and $\left.T_{\mathrm{s}}\right)$, X-ray diffraction, and Raman spectroscopy measurements for structural phase analysis.

\section{Conclusions}

Perovskite type $(1-x) \mathrm{N}_{0.5} \mathrm{~B}_{0.5} \mathrm{TiO}_{3}-x \mathrm{CaTiO}_{3} \quad((1-x)-$ NBT $-x$ CT, $x=0$ and $0.15 \leqslant x \leqslant 0.55)$ lead-free ceramics system were synthesized through solid state route reaction. All the ceramics were sintered in a confined space in order to avoid any loss of $\mathrm{Na} / \mathrm{Bi}$. The effect of $\mathrm{Ca}$ content on the structural, vibrational, and dielectric behaviours was studied in detail. Our results reveal that at room temperature, all the solid solutions are monophasic with perovskite structure. $x=0$ (pure NBT) showed a rhombohedral phase $(R 3 c)$, whereas the entire solid for $0.15 \leqslant x \leqslant 0.55$ presented an orthorhombic symmetry with Pnma as space group. A structural phase transition was revealed through X-ray diffraction and Raman spectroscopy with increasing $x$ at room temperature. The dielectric properties as a function of temperature demonstrated that the $\mathrm{CT}$ substitution in NBT strongly affects the transition temperature $T_{\mathrm{m}}$ by shifting to a lower temperature. A relaxor phenomenon has been highlighted by dielectric characterization where a normal ferroelectric behaviour was obtained for $x=0$ which was transformed to relaxor for $x \geqslant 0.15$. This phenomenon was described by a modified Curie-Weiss law where the value of the diffuseness was around 1.53 and by Vogel-Fulcher relationship. It was related and explained by the presence of local rhombohedral $(R 3 c)$ polar micro- or nanoregions. The anomaly temperature $T_{\mathrm{m}}$ decreased and the paraelectric state was stable even below the room temperature. The specificity of this region-with this type of dopant-was the formation of relaxor at room temperature which indicates that these ceramics are a promising material for many applications.

The phonon behaviour observed as a function of temperature Raman spectra was discussed with X-ray diffraction and dielectric properties. It has been revealed an unexpected diffuse phase transition in this ceramics where the rhombohedral phase was regenerated at low temperature $\left(<-20{ }^{\circ} \mathrm{C}\right.$ for $\left.x=0.15\right)$; the temperatures obtained by dielectric characterization corresponded to the ones obtained by Raman spectroscopy. This transition is attributed to the formation of polar nanoregions (PNRs) where the quantity (which is manifested by the intensity of the characteristic Raman bands) decreases with increasing the temperature. The sequence of phase transition is determined as follows:

$\left(-20{ }^{\circ} \mathrm{C}\right)$ Rhombohedral $R 3 c$ (PNRs) into an orthorhombic matrix $($ Pnma $) \rightarrow\left(25{ }^{\circ} \mathrm{C}\right)$ Orthorhombic $($ Pnma $) \rightarrow\left(360{ }^{\circ} \mathrm{C}\right)$ Orthorhombic + Cubic $($ Pnma + Pm3m).

Moreover, it is also proved by the dispersion study with frequency and Raman spectra at various temperatures that the materials undergo a change in dielectric state from relaxor to paraelectric without a structural transition that remains stable (orthorhombic Pnma) regardless of the temperature.

\section{Acknowledgements}

R. Roukos and the other authors wish to acknowledge the French Ministry of Higher Education and Research and give special thanks to Dr. Fatima Barakat and Nathalie Azar for supporting this work. This work was supported by the Nanosciences Department of Université de Bourgogne.

\section{References}

[1] Ravez J, Simon A. Some solid state chemistry aspects of lead-free relaxor ferroelectrics. J Solid State Chem 2001, 162: 260-265.

[2] Ye Z-G. Relaxor ferroelectric complex perovskites: Structure, properties and phase transitions. Key Eng Mat 1998, 155-156: 81-122.

[3] Ge W, Yao J, DeVreugd C, et al. Electric field dependent phase stability and structurally bridging orthorhombic phase in $\mathrm{Na}_{0.5} \mathrm{Bi}_{0.5} \mathrm{TiO}_{3}-x \% \mathrm{BaTiO}_{3}$ crystals near the MPB. Solid State Commun 2011, 151: 71-74. 
[4] Chen $\mathrm{M}, \mathrm{Xu} \mathrm{Q}, \mathrm{Kim} \mathrm{BH}$, et al. Structure and electrical properties of $\left(\mathrm{Na}_{0.5} \mathrm{Bi}_{0.5}\right)_{1-x} \mathrm{Ba}_{x} \mathrm{TiO}_{3}$ piezoelectric ceramics. J Eur Ceram Soc 2008, 28: 843-849.

[5] Suchanicz J, Jankowska-Sumara I, Kruzina TV. Raman and infrared spectroscopy of $\mathrm{Na}_{0.5} \mathrm{Bi}_{0.5} \mathrm{TiO}_{3}-\mathrm{BaTiO}_{3}$ ceramics. J Electroceram 2011, 27: 45-50.

[6] Chu B-J, Chen D-R, Li G-R, et al. Electrical properties of $\mathrm{Na}_{1 / 2} \mathrm{Bi}_{1 / 2} \mathrm{TiO}_{3}-\mathrm{BaTiO}_{3}$ ceramics. J Eur Ceram Soc 2002, 22: 2115-2121.

[7] Jo W, Daniels JE, Jones JL, et al. Evolving morphotropic phase boundary in lead-free $\left(\mathrm{Bi}_{1 / 2} \mathrm{Na}_{1 / 2}\right) \mathrm{TiO}_{3}-\mathrm{BaTiO}_{3}$ piezoceramics. $J$ Appl Phys 2011, 109: 014110.

[8] Ma C, Guo H, Beckman SP, et al. Creation and destruction of morphotropic phase boundaries through electrical poling: A case study of lead-free $\left(\mathrm{Bi}_{1 / 2} \mathrm{Na}_{1 / 2} \mathrm{TiO}_{3}\right)-\mathrm{BaTiO}_{3}$ piezoelectrics. Phys Rev Lett 2012, 109: 107602.

[9] Gomah-Pettry JR, Marchet P, Salak A, et al. Electrical properties of $\mathrm{Na}_{0.5} \mathrm{Bi}_{0.5} \mathrm{TiO}_{3}-\mathrm{SrTiO}_{3}$ ceramics. Integrated Ferroelectrics 2004, 61: 159-162.

[10] Hiruma Y, Imai Y, Watanabe Y, et al. Large electrostrain near the phase transition temperature of $\left(\mathrm{Bi}_{0.5} \mathrm{Na}_{0.5}\right) \mathrm{TiO}_{3}-$ $\mathrm{SrTiO}_{3}$ ferroelectric ceramics. Appl Phys Lett 2008, 92: 262904.

[11] Rout D, Moon K-S, Kang S-JL, et al. Dielectric and Raman scattering studies of phase transitions in the $(100-x)$ $\mathrm{Na}_{0.5} \mathrm{Bi}_{0.5} \mathrm{TiO}_{3}-x \mathrm{SrTiO}_{3}$ system. $J$ Appl Phys 2010, 108: 084102.

[12] Krauss W, Schütz D, Mautner FA, et al. Piezoelectric properties and phase transition temperatures of the solid solution of $(1-x)\left(\mathrm{Bi}_{0.5} \mathrm{Na}_{0.5}\right) \mathrm{TiO}_{3}-x \mathrm{SrTiO}_{3}$. J Eur Ceram Soc 2010, 30: 1827-1832.

[13] Wang T, Du H, Shi X. Dielectric and ferroelectric properties of $(1-x) \mathrm{Na}_{0.5} \mathrm{Bi}_{0.5} \mathrm{TiO}_{3}-x \mathrm{SrTiO}_{3}$ lead-free piezoceramics system. J Phys: Conf Ser 2009, 152: 012065.

[14] Praharaj S, Rout D, Kar BB, et al. Study of glassy behavior in $60\left(\mathrm{Na}_{0.5} \mathrm{Bi}_{0.5}\right) \mathrm{TiO}_{3}-40 \mathrm{SrTiO}_{3}$ lead-free relaxor. $A I P$ Conference Proceedings 2016, 1731: 140017.

[15] Jin L, Huo R, Guo R, et al. Diffuse phase transitions and giant electrostrictive coefficients in lead-free $\mathrm{Fe}^{3+}$-doped $0.5 \mathrm{Ba}\left(\mathrm{Zr}_{0.2} \mathrm{Ti}_{0.8}\right) \mathrm{O}_{3}-0.5\left(\mathrm{Ba}_{0.7} \mathrm{Ca}_{0.3}\right) \mathrm{TiO}_{3}$ ferroelectric ceramics. ACS Appl Mater Interfaces 2016, 8: 31109-31119.

[16] Zhang L, Xu Z, Li Z, et al. Preparation and characterization of high $T_{\mathrm{c}}(1-x) \mathrm{BiScO}_{3}-x \mathrm{PbTiO}_{3}$ ceramics from high energy ball milling process. $J$ Electroceram 2008, 21: 605-608.

[17] Khansur NH, Glaum J, Clemens $\mathrm{O}$, et al. Uniaxial compressive stress and temperature dependent mechanical behavior of $(1-x) \mathrm{BiFeO}_{3}-x \mathrm{BaTiO}_{3}$ lead-free piezoelectric ceramics. Ceram Int 2017, 43: 9092-9098.

[18] Cheng R, Xu Z, Chu R, et al. Large piezoelectric effect in $\mathrm{Bi}_{1 / 2} \mathrm{Na}_{1 / 2} \mathrm{TiO}_{3}$-based lead-free piezoceramics. Ceram Int 2015, 41: 8119-8127.

[19] Jo W, Daniels J, Damjanovic D, et al. Two-stage processes of electrically induced-ferroelectric to relaxor transition in 0.94 $\left(\mathrm{Bi}_{1 / 2} \mathrm{Na}_{1 / 2}\right) \mathrm{TiO}_{3}-0.06 \mathrm{BaTiO}_{3}$. Appl Phys Lett 2013,
102: 192903.

[20] Bokov AA, Ye Z-G. Recent progress in relaxor ferroelectrics with perovskite structure. J Mater Sci 2006, 41: $31-52$.

[21] Sciau Ph, Calvarin G, Ravez J. X-ray diffraction study of $\mathrm{BaTi}_{0.65} \mathrm{Zr}_{0.35} \mathrm{O}_{3}$ and $\mathrm{Ba}_{0.92} \mathrm{Ca}_{0.08} \mathrm{Ti}_{0.75} \mathrm{Zr}_{0.25} \mathrm{O}_{3}$ compositions: Influence of electric field. Solid State Commun 1999, 113: $77-82$.

[22] Simon A, Ravez J, Maglione M. The crossover from a ferroelectric to a relaxor state in lead-free solid solutions. $J$ Phys: Condens Matter 2004, 16: 963.

[23] Yasuda N, Ohwa H, Arai K, et al. Effect of hydrostatic pressure in barium titanate stannate solid solution $\mathrm{Ba}\left(\mathrm{Ti}_{1-x} \mathrm{Sn}_{x}\right) \mathrm{O}_{3}$. J Mater Sci Lett 1997, 16: 1315-1318.

[24] Chu F, Setter N, Tagantsev AK. The spontaneous relaxor-ferroelectric transition of $\mathrm{Pb}\left(\mathrm{Sc}_{0.5} \mathrm{Ta}_{0.5}\right) \mathrm{O}_{3} . J$ Appl Phys 1993, 74: 5129-5134.

[25] Dai X, Xu Z, Viehland D. The spontaneous relaxor to normal ferroelectric transformation in La-modified lead zirconate titanate. Philos Mag B 1994, 70: 33-48.

[26] Bobnar V, Kutnjak Z, Pirc R, et al. Electric-fieldtemperature phase diagram of the relaxor ferroelectric lanthanum-modified lead zirconate titanate. Phys Rev B 1999, 60: 6420-6427.

[27] Setter N, Cross LE. The role of B-site cation disorder in diffuse phase transition behavior of perovskite ferroelectrics. J Appl Phys 1980, 51: 4356-4360.

[28] Burns G, Dacol FH. Glassy polarization behavior in ferroelectric compounds $\mathrm{Pb}\left(\mathrm{Mg}_{1 / 3} \mathrm{Nb}_{2 / 3}\right) \mathrm{O}_{3}$ and $\mathrm{Pb}\left(\mathrm{Zn}_{1 / 3} \mathrm{Nb}_{2 / 3}\right) \mathrm{O}_{3}$. Solid State Commun 1983, 48: 853-856.

[29] Bonneau P, Garnier P, Calvarin G, et al. X-ray and neutron diffraction studies of the diffuse phase transition in $\mathrm{PbMg}_{1 / 3} \mathrm{Nb}_{2 / 3} \mathrm{O}_{3}$ ceramics. $J$ Solid State Chem 1991, 91: 350-361.

[30] Bonneau P, Garnier P, Husson E, et al. Structural study of PMN ceramics by X-ray diffraction between 297 and 1023 K. Mater Res Bull 1989, 24: 201-206.

[31] Uesu Y, Tazawa H, Fujishiro K, et al. Neutron scattering and nonlinear-optical studies on the phase transition of ferroelectric relaxor $\mathrm{Pb}\left(\mathrm{Mg}_{1 / 3} \mathrm{Nb}_{2 / 3}\right) \mathrm{O}_{3}$. Journal of the Korean Physical Society 1996, 29: S703-S705.

[32] Vakhrushev S, Nabereznov A, Sinha SK, et al. Synchrotron X-ray scattering study of lead magnoniobate relaxor ferroelectric crystals. J Phys Chem Solids 1996, 57: 1517-1523.

[33] Moriya Y, Kawaji H, Tojo T, et al. Specific-heat anomaly caused by ferroelectric nanoregions in $\mathrm{Pb}\left(\mathrm{Mg}_{1 / 3} \mathrm{Nb}_{2 / 3}\right) \mathrm{O}_{3}$ and $\mathrm{Pb}\left(\mathrm{Mg}_{1 / 3} \mathrm{Ta}_{2 / 3}\right) \mathrm{O}_{3}$ relaxors. Phys Rev Lett 2003, 90: 205901.

[34] De Mathan N, Husson E, Calvarn G, et al. A structural model for the relaxor $\mathrm{PbMg}_{1 / 3} \mathrm{Nb}_{2 / 3} \mathrm{O}_{3}$ at $5 \mathrm{~K}$. $J$ Phys: Condens Matter 1991, 3: 8159.

[35] Jeong I-K, Darling TW, Lee JK, et al. Direct observation of the formation of polar nanoregions in $\mathrm{Pb}\left(\mathrm{Mg}_{1 / 3} \mathrm{Nb}_{2 / 3}\right) \mathrm{O}_{3}$ using neutron pair distribution function analysis. Phys Rev 
Lett 2005, 94: 147602.

[36] Xu G, Shirane G, Copley JRD, et al. Neutron elastic diffuse scattering study of $\mathrm{Pb}\left(\mathrm{Mg}_{1 / 3} \mathrm{Nb}_{2 / 3}\right) \mathrm{O}_{3}$. Phys Rev B 2004, 69: 064112.

[37] Shvartsman VV, Kholkin AL, Orlova A, et al. Polar nanodomains and local ferroelectric phenomena in relaxor lead lanthanum zirconate titanate ceramics. Appl Phys Lett 2005, 86: 202907.

[38] You H, Zhang QM. Diffuse X-ray scattering study of lead magnesium niobate single crystals. Phys Rev Lett 1997, 79: 3950 .

[39] La-Orauttapong D, Toulouse J, Robertson JL, et al. Diffuse neutron scattering study of a disordered complex perovskite $\mathrm{Pb}\left(\mathrm{Zn}_{1 / 3} \mathrm{Nb}_{2 / 3}\right) \mathrm{O}_{3}$ crystal. Phys Rev B 2001, 64 : 212101.

[40] Dkhil B, Kiat JM, Calvarin G, et al. Local and long range polar order in the relaxor-ferroelectric compounds $\mathrm{PbMg}_{1 / 3} \mathrm{Nb}_{2 / 3} \mathrm{O}_{3}$ and $\mathrm{PbMg}_{0.3} \mathrm{Nb}_{0.6} \mathrm{Ti}_{0.1} \mathrm{O}_{3}$. Phys Rev $B$ 2001, 65: 024104.

[41] Hirota K, Ye Z-G, Wakimoto S, et al. Neutron diffuse scattering from polar nanoregions in the relaxor $\mathrm{Pb}\left(\mathrm{Mg}_{1 / 3} \mathrm{Nb}_{2 / 3}\right) \mathrm{O}_{3}$. Phys Rev B 2002, 65: 104105 .

[42] Dorcet V, Trolliard G, Boullay P. The structural origin of the antiferroelectric properties and relaxor behavior of $\mathrm{Na}_{0.5} \mathrm{Bi}_{0.5} \mathrm{TiO}_{3}$. J Magn Magn Mater 2009, 321: 17581761.

[43] Lee J-K, Hong KS, Kim CK, et al. Phase transitions and dielectric properties in A-site ion substituted $\left(\mathrm{Na}_{1 / 2} \mathrm{Bi}_{1 / 2}\right) \mathrm{TiO}_{3}$ ceramics (A = Pb and Sr). J Appl Phys 2002, 91: 4538.

[44] Otoničar M, Škapin SD, Spreitzer M, et al. Compositional range and electrical properties of the morphotropic phase boundary in the $\mathrm{Na}_{0.5} \mathrm{Bi}_{0.5} \mathrm{TiO}_{3}-\mathrm{K}_{0.5} \mathrm{Bi}_{0.5} \mathrm{TiO}_{3}$ system. $J$ Eur Ceram Soc 2010, 30: 971-979.

[45] Hiruma Y, Nagata H, Takenaka T. Detection of morphotropic phase boundary of $\left(\mathrm{Bi}_{1 / 2} \mathrm{Na}_{1 / 2}\right) \mathrm{TiO}_{3}-$ $\mathrm{Ba}\left(\mathrm{Al}_{1 / 2} \mathrm{Sb}_{1 / 2}\right) \mathrm{O}_{3}$ solid-solution ceramics. Appl Phys Lett 2009, 95: 052903.

[46] Watanabe Y, Hiruma Y, Nagata H, et al. Phase transition temperatures and electrical properties of divalent ions $\left(\mathrm{Ca}^{2+}\right.$, $\mathrm{Sr}^{2+}$ and $\left.\mathrm{Ba}^{2+}\right)$ substituted $\left(\mathrm{Bi}_{1 / 2} \mathrm{Na}_{1 / 2}\right) \mathrm{TiO}_{3}$ ceramics. Ceram Int 2008, 34: 761-764.

[47] Yuan Y, Li EZ, Li B, et al. Effects of Ca and Mn additions on the microstructure and dielectric properties of $\left(\mathrm{Bi}_{0.5} \mathrm{Na}_{0.5}\right) \mathrm{TiO}_{3}$ ceramics. J Electron Mater 2011, 40: 2234-2239.

[48] Ranjan R, Garg R, Kothai V, et al. Phases in the $(1-x) \mathrm{Na}_{0.5} \mathrm{Bi}_{0.5} \mathrm{TiO}_{3}-(x) \mathrm{CaTiO}_{3}$ system. $J$ Phys: Condens Matter 2010, 22: 075901.

[49] Du HL, Du X, Li HL. Phase structure and electrical properties of lead free $\mathrm{Na}_{0.5} \mathrm{Bi}_{0.5} \mathrm{TiO}_{3}-\mathrm{CaTiO}_{3}$ ceramics. Adv Appl Ceram 2013, 112: 277-281.

[50] Birks E, Dunce M, Ignatans R, et al. Structure and dielectric properties of $\mathrm{Na}_{0.5} \mathrm{Bi}_{0.5} \mathrm{TiO}_{3}-\mathrm{CaTiO}_{3}$ solid solutions. J Appl Phys 2016, 119: 074102.

[51] Aksel E, Forrester JS, Jones JL, et al. Monoclinic crystal structure of polycrystalline $\mathrm{Na}_{0.5} \mathrm{Bi}_{0.5} \mathrm{TiO}_{3}$. Appl Phys Lett 2011, 98: 152901.

[52] Roukos R. Transitions de phases dans des oxydes complexes de structure pérovskite: cas du système $(1-x) \mathrm{Na}_{0.5} \mathrm{Bi}_{0.5} \mathrm{TiO}_{3}-x \mathrm{CaTiO}_{3}$. Université de Bourgogne, 2015.

[53] Roukos R, Geoffroy N, Chaumont D. Electric field induced monoclinic phase stability in $\mathrm{Ca}$ doped $\mathrm{Na}_{0.5} \mathrm{Bi}_{0.5} \mathrm{TiO}_{3}$ : Case of $0.93 \mathrm{Na}_{0.5} \mathrm{Bi}_{0.5} \mathrm{TiO}_{3}-0.07 \mathrm{CaTiO}_{3}$ ferroelectric ceramics. AIP Advances 2017, 7: 015030.

[54] Craciun F, Galassi C, Birjega R. Electric-field-induced and spontaneous relaxor-ferroelectric phase transitions in $\left(\mathrm{Na}_{1 / 2} \mathrm{Bi}_{1 / 2}\right)_{1-x} \mathrm{Ba}_{x} \mathrm{TiO}_{3}$. J Appl Phys 2012, 112: 124106.

[55] Parija B, Badapanda T, Rout SK, et al. Morphotropic phase boundary and electrical properties of $1-x\left[\mathrm{Bi}_{0.5} \mathrm{Na}_{0.5}\right] \mathrm{TiO}_{3}-$ $x \mathrm{Ba}\left[\mathrm{Zr}_{0.25} \mathrm{Ti}_{0.75}\right] \mathrm{O}_{3}$ lead-free piezoelectric ceramics. Ceram Int 2013, 39: 4877-4886.

[56] Zheng H, Csete de Györgyfalva GDC, Quimby R, et al. Raman spectroscopy of B-site order-disorder in $\mathrm{CaTiO}_{3^{-}}$ based microwave ceramics. J Eur Ceram Soc 2003, 23: 2653-2659.

[57] Selvamani R, Singh G, Sathe V, et al. Dielectric, structural and Raman studies on $\left(\mathrm{Na}_{0.5} \mathrm{Bi}_{0.5} \mathrm{TiO}_{3}\right)_{(1-x)}\left(\mathrm{BiCrO}_{3}\right)_{x}$ ceramic. J Phys: Condens Matter 2011, 23: 055901.

[58] Xu C, Lin D, Kwok KW. Structure, electrical properties and depolarization temperature of $\left(\mathrm{Bi}_{0.5} \mathrm{Na}_{0.5}\right) \mathrm{TiO}_{3}-\mathrm{BaTiO}_{3}$ lead-free piezoelectric ceramics. Solid State Sci 2008, 10: 934-940.

[59] Sapper E, Schaab S, Jo W, et al. Influence of electric fields on the depolarization temperature of Mn-doped (1-x)$\mathrm{Bi}_{1 / 2} \mathrm{Na}_{1 / 2} \mathrm{TiO}_{3}-x \mathrm{BaTiO}_{3}$. J Appl Phys 2012, 111: 014105.

[60] Jo W, Schaab S, Sapper E, et al. On the phase identity and its thermal evolution of lead free $\left(\mathrm{Bi}_{1 / 2} \mathrm{Na}_{1 / 2}\right) \mathrm{TiO}_{3}-6 \mathrm{~mol} \%$ $\mathrm{BaTiO}_{3}$. J Appl Phys 2011, 110: 074106.

[61] Barick BK, Mishra KK, Arora AK, et al. Impedance and Raman spectroscopic studies of $\left(\mathrm{Na}_{0.5} \mathrm{Bi}_{0.5}\right) \mathrm{TiO}_{3}$. J Phys D: Appl Phys 2011, 44: 355402.

[62] Bai W, Chen D, Zheng P, et al. Composition- and temperature-driven phase transition characteristics and associated electromechanical properties in $\mathrm{Bi}_{0.5} \mathrm{Na}_{0.5} \mathrm{TiO}_{3-}$ based lead-free ceramics. Dalton Trans 2016, 45: 85738586.

[63] Bai W, Chen D, Zheng P, et al. $\mathrm{NaNbO}_{3}$ templates-induced phase evolution and enhancement of electromechanical properties in $<001>$ grain oriented lead-free BNT-based piezoelectric materials. J Eur Ceram Soc 2017, 37: 25912604.

[64] Wang K, Hussain A, Jo W, et al. Temperature-dependent properties of $\left(\mathrm{Bi}_{1 / 2} \mathrm{Na}_{1 / 2}\right) \mathrm{TiO}_{3}-\left(\mathrm{Bi}_{1 / 2} \mathrm{~K}_{1 / 2}\right) \mathrm{TiO}_{3}-\mathrm{SrTiO}_{3}$ lead-free piezoceramics. J Am Ceram Soc 2012, 95: 22412247.

[65] Chu B-J, Chen D-R, Li G-R, et al. Electrical properties of $\mathrm{Na}_{1 / 2} \mathrm{Bi}_{1 / 2} \mathrm{TiO}_{3}-\mathrm{BaTiO}_{3}$ ceramics. J Eur Ceram Soc 2002, 22: 2115-2121.

[66] Oh T. Dielectric relaxor properties in the system of 
$\left(\mathrm{Na}_{1-x} \mathrm{~K}_{x}\right)_{1 / 2} \mathrm{Bi}_{1 / 2} \mathrm{TiO}_{3}$ ceramics. Jpn J Appl Phys 2006, 45: 5138.

[67] Jarupoom P, Pengpat K, Pisitpipathsin N, et al. Development of electrical properties in lead-free bismuth sodium lanthanum titanate-barium titanate ceramic near the morphotropic phase boundary. Curr Appl Phys 2008, 8: 253-257.

[68] Singh AK, Pandey D. Evidence for $M_{\mathrm{B}}$ and $M_{\mathrm{C}}$ phases in the morphotropic phase boundary region of $(1-x)$ $\left[\mathrm{Pb}\left(\mathrm{Mg}_{1 / 3} \mathrm{Nb}_{2 / 3}\right) \mathrm{O}_{3}\right]-x \mathrm{PbTiO}_{3}$ : A Rietveld study. Phys Rev B 2003, 67: 064102.

[69] Ma HY, Chen XM, Wang J, et al. Structure, dielectric and ferroelectric properties of $0.92 \mathrm{Na}_{0.5} \mathrm{Bi}_{0.5} \mathrm{TiO}_{3}-0.06 \mathrm{BaTiO}_{3}-$ $0.02 \mathrm{~K}_{0.5} \mathrm{Na}_{0.5} \mathrm{NbO}_{3}$ lead-free ceramics: Effect of $\mathrm{Co}_{2} \mathrm{O}_{3}$ additive. Ceram Int 2013, 39: 3721-3729.

[70] Li Y, Chen W, Zhou J, et al. Dielectric and ferroelectric properties of lead-free $\mathrm{Na}_{0.5} \mathrm{Bi}_{0.5} \mathrm{TiO}_{3}-\mathrm{K}_{0.5} \mathrm{Bi}_{0.5} \mathrm{TiO}_{3}$ ferroelectric ceramics. Ceram Int 2005, 31: 139-142.

[71] Talik B. Ferroelectric relaxor behavior and spectroscopic properties of $\mathrm{Ba}^{2+}$ and $\mathrm{Zr}^{4+}$ modified sodium bismuth titanate. Am J Mater Sci 2012, 2: 110-118.

[72] Tagantsev AK. Vogel-Fulcher relationship for the dielectric permittivity of relaxor ferroelectrics. Phys Rev Lett 1994, 72: 1100.

[73] Grigalaitis R, Ivanov M, Macutkevic J, et al. Size effects in a relaxor: Further insights into PMN. J Phys: Condens Matter 2014, 26: 272201.

[74] Liu J, Duan C-G, Yin W-G, et al. Dielectric permittivity and electric modulus in $\mathrm{Bi}_{2} \mathrm{Ti}_{4} \mathrm{O}_{11}$. J Chem Phys 2003, 119: 2812-2819.

[75] Grigalaitis R, Banys J, Kania A, et al. Distribution of relaxation times in PMN single crystal. J Phys IV France 2005, 128: 127-131.

[76] Kreisel J, Glazer AM, Bouvier P, et al. High-pressure Raman study of a relaxor ferroelectric: The $\mathrm{Na}_{0.5} \mathrm{Bi}_{0.5} \mathrm{TiO}_{3}$ perovskite. Phys Rev B 2001, 63: 174106.

[77] Luo L, Ge W, Li J, et al. Raman spectroscopic study of $\mathrm{Na}_{1 / 2} \mathrm{Bi}_{1 / 2} \mathrm{TiO}_{3}-x \% \mathrm{BaTiO}_{3}$ single crystals as a function of temperature and composition. J Appl Phys 2011, 109: 113507.

[78] Aksel E, Forrester JS, Kowalski B, et al. Structure and properties of Fe-modified $\mathrm{Na}_{0.5} \mathrm{Bi}_{0.5} \mathrm{TiO}_{3}$ at ambient and elevated temperature. Phys Rev B 2012, 85: 024121.

[79] Bai W, Li P, Li L, et al. Structure evolution and large strain response in BNT-BT lead-free piezoceramics modified with $\mathrm{Bi}\left(\mathrm{Ni}_{0.5} \mathrm{Ti}_{0.5}\right) \mathrm{O}_{3}$. J Alloys Compd 2015, 649: 772-781.

[80] Wakimoto S, Stock C, Birgeneau RJ, et al. Ferroelectric ordering in the relaxor $\mathrm{Pb}\left(\mathrm{Mg}_{1 / 3} \mathrm{Nb}_{2 / 3}\right) \mathrm{O}_{3}$ as evidenced by low-temperature phonon anomalies. Phys Rev B 2002, 65: 172105.

[81] Li F, Zuo R, Zheng D, et al. Phase-composition-dependent piezoelectric and electromechanical strain properties in $\left(\mathrm{Bi}_{1 / 2} \mathrm{Na}_{1 / 2}\right) \mathrm{TiO}_{3}-\mathrm{Ba}\left(\mathrm{Ni}_{1 / 2} \mathrm{Nb}_{1 / 2}\right) \mathrm{O}_{3}$ lead-free ceramics. $J$ Am Ceram Soc 2015, 98: 811-818.

[82] Schütz D, Deluca M, Krauss W, et al. Lone-pair-induced covalency as the cause of temperature- and field-induced instabilities in bismuth sodium titanate. Adv Funct Mater 2012, 22: 2285-2294.

[83] Sasaki A, Chiba T, Mamiya Y, et al. Dielectric and piezoelectric properties of $\left(\mathrm{Bi}_{0.5} \mathrm{Na}_{0.5}\right) \mathrm{TiO}_{3}-\left(\mathrm{Bi}_{0.5} \mathrm{~K}_{0.5}\right) \mathrm{TiO}_{3}$ systems. Jpn J Appl Phys 1999, 38: 5564.

[84] Ragini, Ranjan R, Mishra SK, et al. Room temperature structure of $\mathrm{Pb}\left(\mathrm{Zr}_{x} \mathrm{Ti}_{1-x} \mathrm{O}_{3}\right)$ around the morphotropic phase boundary region: A Rietveld study. J Appl Phys 2002, 92: 3266-3274.

[85] Daniels JE, Jo W, Rödel J, et al. Electric-field-induced phase transformation at a lead-free morphotropic phase boundary: Case study in a $93 \%\left(\mathrm{Bi}_{0.5} \mathrm{Na}_{0.5}\right) \mathrm{TiO}_{3}-7 \% \mathrm{BaTiO}_{3}$ piezoelectric ceramic. Appl Phys Lett 2009, 95: 032904.

[86] Viehland D, Wuttig M, Cross LE. The glassy behavior of relaxor ferroelectrics. Ferroelectrics 1991, 120: 71-77.

[87] Hiruma Y, Nagata H, Takenaka T. Thermal depoling process and piezoelectric properties of bismuth sodium titanate ceramics. J Appl Phys 2009, 105: 084112.

Open Access The articles published in this journal are distributed under the terms of the Creative Commons Attribution 4.0 International License (http://creativecommons.org/licenses/by/4.0/), which permits unrestricted use, distribution, and reproduction in any medium, provided you give appropriate credit to the original author(s) and the source, provide a link to the Creative Commons license, and indicate if changes were made. 